\title{
A multitrophic perspective on biodiversity-ecosystem functioning research
}

Nico Eisenhauer ${ }^{a, b}, *$, Holger Schielzeth ${ }^{a, c}$, Andrew D. Barnes ${ }^{a, b}$,

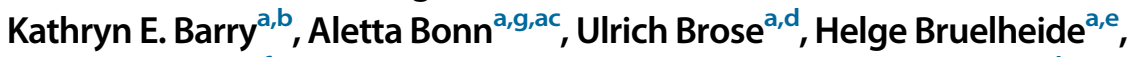
Nina Buchmann ${ }^{\mathrm{f}}$, François Buscot ${ }^{\mathrm{a}, \mathrm{g}}$, Anne Ebeling ${ }^{\mathrm{c}}$, Olga Ferlian ${ }^{\mathrm{a}, \mathrm{b}}$, Grégoire T. Freschet ${ }^{h}$, Darren P. Giling ${ }^{\mathrm{a}, \mathrm{b}, \mathrm{c}}$, Stephan Hättenschwiler ${ }^{\mathrm{h}}$, Helmut Hillebrand $^{a, i, a h}$, Jes Hines ${ }^{a, b}$, Forest Isbelli, Eva Koller-France ${ }^{k}$, Birgitta König-Ries $^{\mathrm{a}, \mathrm{l}}$, Hans de Kroon ${ }^{\mathrm{m}}$, Sebastian T. Meyer ${ }^{\mathrm{n}}$, Alexandru Milcu $^{\text {h,o }}$, Jörg Müller ${ }^{p, q}$, Charles A. Nock ${ }^{r, s}$, Jana S. Petermann ${ }^{\mathrm{t}}$, Christiane Roscher ${ }^{\mathrm{a}, \mathrm{u}}$, Christoph Scherber ${ }^{\mathrm{v}}$, Michael Scherer-Lorenzen ${ }^{r}$, Bernhard Schmid"w, Stefan A. Schnitzer ${ }^{x}$, Andreas Schuldt ${ }^{y}$, Teja Tscharntke ${ }^{z, a a}$, Manfred Türke ${ }^{a, b, a b}$, Nicole M. van Dam ${ }^{\mathrm{a}, \mathrm{ac}}$, Fons van der Plas ${ }^{\mathrm{b}}$, Anja Vogel ${ }^{\mathrm{a}, \mathrm{b}, \mathrm{c}}$, Cameron Wagg ${ }^{\text {ad,ae }}$, David A. Wardle ${ }^{\text {af }}$, Alexandra Weigelt ${ }^{\mathrm{a}, \mathrm{b}}$, Wolfgang W. Weisser ${ }^{n}$, Christian Wirth ${ }^{\mathrm{a}}$, Malte Jochum ${ }^{\mathrm{a}, \mathrm{b}, \mathrm{ag}}$

${ }^{a}$ German Centre for Integrative Biodiversity Research (iDiv) Halle-Jena-Leipzig, Leipzig, Germany

${ }^{\mathrm{b}}$ Institute of Biology, Leipzig University, Leipzig, Germany

${ }^{c}$ Institute of Ecology and Evolution, Friedrich Schiller University Jena, Jena, Germany

${ }^{d}$ EcoNetLab, Institute of Biodiversity, Friedrich Schiller University Jena, Jena, Germany

${ }^{\mathrm{e}}$ Institute of Biology/Geobotany and Botanical Garden, Martin Luther University Halle-Wittenberg, Halle (Saale), Germany

${ }^{\mathrm{f} I n s t i t u t e}$ of Agricultural Sciences, ETH Zürich, Zürich, Switzerland

${ }^{\mathrm{g}}$ UFZ - Helmholtz Centre for Environmental Research, Soil Ecology Department, Halle (Saale), Germany

${ }^{\text {h}}$ Centre d'Ecologie Fonctionnelle et Evolutive, UMR 5175 (CNRS-Université de Montpellier-Université Paul-Valéry Montpellier-EPHE), Montpellier, France

${ }^{\mathrm{i}}$ Institute for Chemistry and Biology of Marine Environments [ICBM], Carl-von-Ossietzky University Oldenburg, Wilhelmshaven, Germany

${ }^{\mathrm{j}}$ Department of Ecology, Evolution and Behavior, University of Minnesota, St. Paul, MN, United States

${ }^{\mathrm{k}}$ Karlsruher Institut für Technologie (KIT), Institut für Geographie und Geoökologie, Karlsruhe, Germany

${ }^{1}$ Institute of Computer Science, Friedrich Schiller Universität Jena, Jena, Germany

${ }^{\mathrm{m}}$ Radboud University, Institute for Water and Wetland Research, Animal Ecology and Physiology \&

Experimental Plant Ecology, Nijmegen, The Netherlands

${ }^{\mathrm{n}}$ Terrestrial Ecology Research Group, Technical University of Munich, School of Life Sciences

Weihenstephan, Freising, Germany

${ }^{\circ}$ Ecotron Européen de Montpellier, Centre National de la Recherche Scientifique (CNRS), Montferrier-surLez, France

${ }^{\mathrm{P}}$ Field Station Fabrikschleichach, Department of Animal Ecology and Tropical Biology, Biocenter, University of Würzburg, Rauhenebrach, Germany

${ }^{\mathrm{q}}$ Bavarian Forest National Park, Grafenau, Germany

${ }^{\mathrm{r}}$ Geobotany, Faculty of Biology, University of Freiburg, Freiburg, Germany

${ }^{\mathrm{s}}$ Department of Renewable Resources, University of Alberta, Edmonton, AB, Canada 
${ }^{\mathrm{t}}$ Department of Biosciences, University of Salzburg, Salzburg, Austria

${ }^{\mathrm{u} U F Z-H e l m h o l t z}$ Centre for Environmental Research, Department Physiological Diversity, Leipzig,

Germany

${ }^{\mathrm{v}}$ Institute of Landscape Ecology, University of Münster, Münster, Germany

${ }^{\mathrm{w}}$ Department of Geography, University of Zürich, Zürich, Switzerland

${ }^{\mathrm{x}}$ Department of Biology, Marquette University, Milwaukee, WI, United States

${ }^{\mathrm{y}}$ Forest Nature Conservation, Faculty of Forest Sciences and Forest Ecology, University of Göttingen, Göttingen, Germany

${ }^{z}$ Department of Crop Sciences, Division of Agroecology, University of Göttingen, Göttingen, Germany ${ }^{a a}$ Centre of Biodiversity and Sustainable Land Use (CBL), University of Göttingen, Göttingen, Germany

${ }^{\mathrm{ab}}$ Institute of Biological and Medical Imaging (IBMI), Helmholtz Zentrum München (HMGU)—German

Research Center for Environmental Health, Neuherberg, Germany

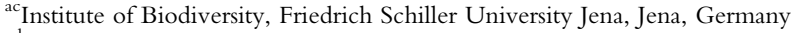

${ }^{\mathrm{ad}}$ Fredericton Research and Development Centre, Agriculture and Agri-Food Canada, Fredericton, NB,

Canada

${ }^{\text {ae }}$ Department of Evolutionary Biology and Environmental Studies, University of Zürich, Zürich, Switzerland

${ }^{a f}$ Asian School of the Environment, Nanyang Technological University, Singapore, Singapore

${ }^{\mathrm{ag}}$ Institute of Plant Sciences, University of Bern, Bern, Switzerland

${ }^{\text {ah }}$ Helmholtz-Institute for Functional Marine Biodiversity at the University of Oldenburg (HIFMB),

Oldenburg, Germany

*Corresponding author: e-mail address: nico.eisenhauer@idiv.de

\section{Contents}

1. What are the key achievements of BEF research? 3

1.1 A short history of BEF research 5

1.2 A new BEF era provides novel insights 8

1.3 Identification of BEF mechanisms 9

$\begin{array}{lr}1.4 \text { BEF in multitrophic communities } & 10\end{array}$

$\begin{array}{ll}\text { 1.5 BEF implications for ecosystem services } & 11\end{array}$

2. What are the key challenges of future BEF research? 12

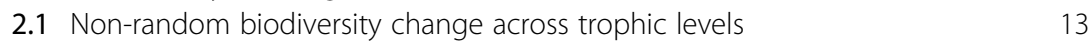

$\begin{array}{ll}\text { 2.2 Predicting the strength of BEF relationships across environmental contexts } & 19\end{array}$

2.3 Spatial scaling of BEF relationships 23

2.4 Eco-evolutionary implications of multitrophic BEF 26

2.5 FAIR data and beyond 29

2.6 Operationalizing BEF insights for ecosystem management, society, and decision making

3. Concluding remarks 33

Acknowledgements $\quad 34$

References $\quad 34$

\section{Abstract}

Concern about the functional consequences of unprecedented loss in biodiversity has prompted biodiversity-ecosystem functioning (BEF) research to become one of the most active fields of ecological research in the past 25 years. Hundreds of experiments have manipulated biodiversity as an independent variable and found compelling support that the functioning of ecosystems increases with the diversity of their ecological 
communities. This research has also identified some of the mechanisms underlying BEF relationships, some context-dependencies of the strength of relationships, as well as implications for various ecosystem services that humankind depends upon. In this chapter, we argue that a multitrophic perspective of biotic interactions in random and non-random biodiversity change scenarios is key to advance future BEF research and to address some of its most important remaining challenges. We discuss that the study and the quantification of multitrophic interactions in space and time facilitates scaling up from small-scale biodiversity manipulations and ecosystem function assessments to management-relevant spatial scales across ecosystem boundaries. We specifically consider multitrophic conceptual frameworks to understand and predict the context-dependency of BEF relationships. Moreover, we highlight the importance of the eco-evolutionary underpinnings of multitrophic BEF relationships. We outline that FAIR data (meeting the standards of findability, accessibility, interoperability, and reusability) and reproducible processing will be key to advance this field of research by making it more integrative. Finally, we show how these BEF insights may be implemented for ecosystem management, society, and policy. Given that human well-being critically depends on the multiple services provided by diverse, multitrophic communities, integrating the approaches of evolutionary ecology, community ecology, and ecosystem ecology in future BEF research will be key to refine conservation targets and develop sustainable management strategies.

\section{What are the key achievements of BEF research?}

"The community is indeed the hierarchical level where the basic characteristics of life-its diversity, complexity, and historical nature-are perhaps the most daunting and challenging. [...] however, most of the theoretical insights that have been gained about the effects of biodiversity on ecosystem functioning come from approaches developed in community ecology."

Loreau (2010)

Human activities influence virtually all ecosystems around the globe through a large variety of environmental alterations (MEA, 2005). Habitat destruction (Maxwell et al., 2016), changing and intensified land use (Gossner et al., 2016; Newbold et al., 2015), climate change (Urban et al., 2016), and invasion of exotic species (Murphy and Romanuk, 2014; van Kleunen et al., 2015; Vitousek et al., 1997; Wardle et al., 2011) are some of the most significant drivers of biodiversity change (Maxwell et al., 2016). Subsequent changes in ecological communities raise substantial ethical and aesthetic concerns as well as questions regarding the functioning of altered ecosystems (Hooper et al., 2005; Isbell et al., 2017a; Naeem et al., 2012). Biodiversity-ecosystem 
functioning (BEF) research has revealed strong positive effects of biodiversity on various ecosystem functions, and has linked these effects to underlying mechanisms. Positive BEF relationships can be observed at different spatial (Cardinale et al., 2012; Hautier et al., 2018; Isbell et al., 2011; Roscher et al., 2005; Thompson et al., 2018; van der Plas et al., 2016a,b) and temporal scales (Guerrero-Ramírez et al., 2017; Reich et al., 2012; Zavaleta et al., 2010), and can be multi-dimensional on both the predictor (i.e., multidiversity) and response side (multifunctionality) (e.g., Hector and Bagchi, 2007; Meyer et al., 2018; Schuldt et al., 2018; Soliveres et al., 2016a). Accordingly, one of the most important conclusions of BEF research is that the strength of BEF relationships is strongly context-dependent. BEF relationships have been shown to depend on climatic conditions (Maestre et al., 2012; Ratcliffe et al., 2017), local site conditions (Allan et al., 2015; Eisenhauer et al., 2018; Fridley, 2002; Reich et al., 2001), and disturbance and management regimes (Guerrero-Ramírez et al., 2017; Kardol et al., 2018; Weigelt et al., 2009), which interact with biodiversity (Guerrero-Ramírez and Eisenhauer, 2017; but see Craven et al., 2016). Accordingly, mechanisms underlying biodiversity effects have been found to differ from one community to the next. Before discussing how the status quo can inspire future research to address some of the most important challenges in BEF research and ecology in general, we provide an overview of key achievements of past BEF work.

This chapter is based on a survey among researchers in the Jena Experiment, of a workshop on the "Future of BEF research" organized in the framework of the Jena Experiment, and of the German Centre for Integrative Biodiversity Research (iDiv) and thus has a bias towards BEF research in terrestrial ecosystems and in controlled experiments. Rather than proving a comprehensive picture of all important research directions in BEF and how these directions may have developed since past reviews (e.g., Cardinale et al., 2012; Hillebrand and Matthiessen, 2009; Hooper et al., 2005; Loreau et al., 2001; Naeem et al., 2012; Scherer-Lorenzen, 2014; Tilman et al., 2014; van der Plas, 2019; Weisser et al., 2017), we focus on the key aspects that materialized from the survey. In December 2016, all researchers were asked to answer the following two questions:

- What are the key achievements of past BEF research?

- What are the key challenges/topics of future BEF research? Where should the field move?

Contributions were synthesized by N.E. and discussed at the "Future of BEF research"-workshop in Jena, Germany in February 2017. As an outcome, we highlight six priority areas of future BEF research, namely non-random 
biodiversity change across trophic levels; predicting the strength of BEF relationships across environmental contexts; spatial scaling of BEF relationships; eco-evolutionary implications of multitrophic BEF; FAIR data and reproducible processing; and operationalizing BEF insights for ecosystem management, society, and decision making.

\subsection{A short history of BEF research}

Prior to the era of BEF research, nature conservation efforts targeted biodiversity separately from ecosystem functioning. On the one hand, the goal of conservation was to prevent species extinctions (Mace, 2014). On the other hand, ecosystems were protected and managed to conserve and maximize their functions and services (such as forests for groundwater recharge, erosion control, or recreation), but without explicit consideration of their diversity (Costanza et al., 1997). Conservation had mostly been ethically motivated, while BEF research moved the argument to take a utilitarian view of biodiversity to convince target groups like politicians and land managers. Although, there was a consensus that it was important to protect different species and certain functions, these aims were, and still are in many places of the world, regarded as poorly connected, as well as insufficiently linked to ecological theory. BEF research helped to provide an empirical underpinning for these inherently related objects, thus adding an important justification for conserving biodiversity that went beyond ethical and aesthetic motivations (Dallimer et al., 2012; Potthast, 2014).

Early observations of natural communities inspired the notion that biodiversity may be a key determinant of the functioning of ecosystems (Darwin and Wallace, 1858; Elton, 1958; McNaughton, 1977; Schulze and Mooney, 1994). This idea was supported by theoretical models (Loreau, 1998; Tilman et al., 1997a; Yachi and Loreau, 1999) and experiments (Hooper et al., 2005; O'Connor et al., 2017). In fact, over the past 25 years, BEF research has led us to recognize that the identity and combinations of species are powerful drivers of ecosystem processes (Hooper et al., 2005; Isbell et al., 2017a; Schulze and Mooney, 1994; Tilman et al., 2014; Weisser et al., 2017).

More specifically, prior to the mid-1990s, ecologists focused more on abiotic factors driving variation in biodiversity, such as geology and climate, than biotic factors, such as species diversity and species interactions (Hobbie, 1992). Early topical questions were related to the environmental determinants of biodiversity (Fig. 1; van der Plas, 2019). The search for 

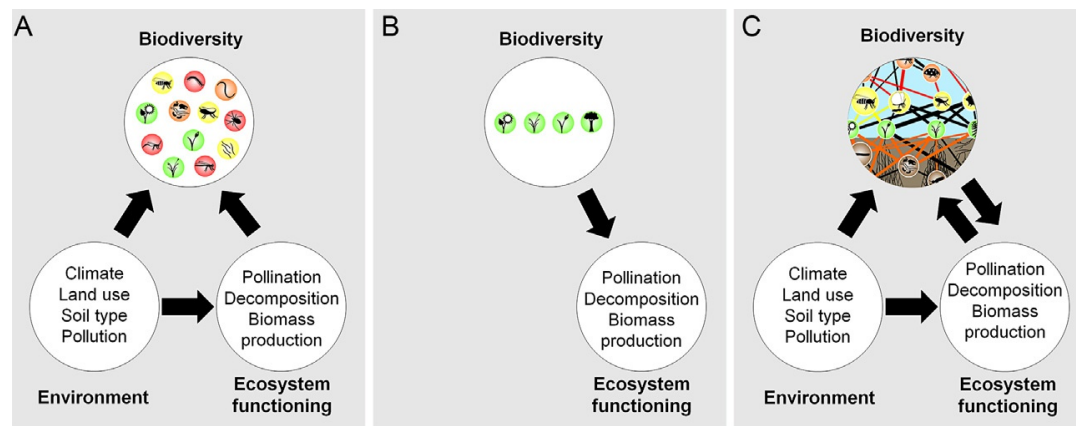

Fig. 1 The evolution of biodiversity research. Main foci of biodiversity-ecosystem functioning research over time (Chapin et al., 2000; De Laender et al., 2016; Eisenhauer et al., 2016; Isbell et al., 2013; van der Plas, 2019). While studying example environmental drivers of different facets of biodiversity and ecosystem functioning has been an important subdiscipline in ecological research for many decades (i.e., community ecology) (A), in the mid-1990s, researchers started to manipulate biodiversity (mostly at the producer level; mostly random biodiversity loss scenarios) as an independent variable (functional biodiversity research or BEF research) (B). More recently, ecologists started focusing on the complex interplay between anthropogenically driven environmental gradients, nonrandom biodiversity change across trophic levels in food webs (C) (see also Fig. 2), and the consequences for ecosystem function (e.g., Barnes et al., 2018; De Laender et al., 2016; Hines et al., 2019; Mori et al., 2013; Sobral et al., 2017; Soliveres et al., 2016a) (C). Figure modified after van der Plas, F., 2019.

answers to these fundamental questions in biodiversity yielded major scientific achievements, such as Darwin's theory of evolution (Darwin, 1859), Hutchinson's concept of the ecological niche (Hutchinson, 1957), and MacArthur and Wilson's theory of island biogeography (MacArthur and Wilson, 1967; summarized in Craven et al., 2019). Still today, the exploration of the determinants of biodiversity is a crucial field in ecology (e.g., Adler et al., 2011), which is important to some of the most pressing challenges of humankind, particularly given the unprecedented rate of anthropogenic environmental change.

While the importance of species diversity to ecosystem functioning was recognized more than 150 years ago; e.g., Darwin and Wallace (1858) stated “... it has been experimentally shown that a plot of land will yield a greater weight if sown with several species and genera of grasses, than if sown with only two or three species", this recognition of the importance of biodiversity took a back seat (Hector and Hooper, 2002). In fact, one of the first experiments of the 20th century reporting on BEF relationships was originally designed to study how different concentrations of nitrogen drive plant 
diversity (Tilman and Downing, 1994). However, when these plant communities were unexpectedly hit by an extreme drought, it became evident that the response to the extreme event and the stability of the ecosystem function "plant productivity" depended on the species richness of the community (Tilman and Downing, 1994). This study showed a positive biodiversity-stability relationship, but was criticized because it did not manipulate biodiversity as an independent factor, meaning that stability of plant biomass production was likely (co-)determined by the nitrogen treatment (Givnish, 1994; Huston, 1997). After the first "wave" of scientific debate, Grime (1997) concluded that "...neither evolutionary theory nor empirical studies have presented convincing evidence that species diversity and ecosystem function are consistently and causally connected."

This debate stimulated a series of controlled experiments that directly manipulated biodiversity aiming to quantify the effect of plant species richness on ecosystem functioning under controlled environmental conditions (e.g., Díaz et al., 2003; Ebeling et al., 2014; Hector et al., 1999; Hooper et al., 2005; Naeem et al., 1994; Niklaus et al., 2001; O'Connor et al., 2017; Roscher et al., 2004; Tilman et al., 1997b; Wardle and Zackrisson, 2005; Fig. 1). The results were surprisingly clear: community biomass production, in particular, increased with an increasing number of plant species (Hooper et al., 2005). Subsequent debates (e.g., Eisenhauer et al., 2016; Wardle, 2016) and adjustments of experimental designs stimulated the collection of evidence that BEF relationships could occur irrespective of the inclusion of certain species, functional groups, or combinations of species (Eisenhauer et al., 2016; Huang et al., 2018; van Ruijven and Berendse, 2003; Wilsey and Polley, 2004).

The focus on the manipulation of plant diversity and productivity, however, led to calls, and actions, to study a wider range of taxa and functions. Subsequently, BEF research became more integrative in terms of scientific disciplines by realizing that a whole-ecosystem perspective, including, e.g., multitrophic interactions and element cycles, is required to explore the mechanistic underpinnings and implications of biodiversity change (Roscher et al., 2004; Schuldt et al., 2018). Nonetheless, these experiments have also provoked debate over their realism. Randomlyassembled communities may not mirror real-world assembly and disassembly (Lepš, 2004; Wardle, 2016), which are determined by the simultaneous interplay of abiotic and biotic filters in time and space (Götzenberger et al., 2012). Some recent experiments thus shifted their focus from the number of species to the functional and phylogenetic dissimilarity of species 
assemblages (Cadotte, 2013; Dias et al., 2013; Ebeling et al., 2014; Ferlian et al., 2018; Scherer-Lorenzen et al., 2007) or have implemented nonrandom biodiversity loss scenarios (e.g., Bracken et al., 2008; Bruelheide et al., 2014; Schläpfer et al., 2005).

Non-random changes in biodiversity and the notion that the strength of BEF relationships is context-dependent (Baert et al., 2018; GuerreroRamírez et al., 2017; Ratcliffe et al., 2017) have led contemporary BEF research to re-introduce non-random and indirect manipulations of biodiversity using environmental change drivers, such as various climate variables, management intensity, chemical pollutants, and nutrient enrichment, as well as observations along environmental gradients (De Laender et al., 2016; Everwand et al., 2014; Grace et al., 2016; Isbell et al., 2013; Fig. 1). Although empirical evidence is limited to date, the findings of, e.g., Duffy et al. (2017) and Isbell et al. (2013) substantiate the general predictions from BEF experiments by demonstrating that the repeatedly-reported discrepancies in results between experimental and real-world BEF studies may, in fact, be due to multiple interacting or unrecognized drivers typically operating in real-world systems (De Laender et al., 2016; Eisenhauer et al., 2016; Loreau, 1998).

\subsection{A new BEF era provides novel insights}

In the last $\sim 10$ years, multiple review papers on BEF relationships have comprehensively summarized the major achievements and novel insights by BEF research (e.g., Balvanera et al., 2006; Cardinale et al., 2012; Dirzo et al., 2014; Hooper et al., 2005; Isbell et al., 2017a; Loreau et al., 2001; Naeem et al., 2012; Scherer-Lorenzen, 2014; Tilman et al., 2014; van der Plas, 2019; Weisser et al., 2017). Briefly, this research has shown the importance of biodiversity (from microorganisms to trees, but mostly of primary producers) in driving the functioning of ecosystems, with functions ranging from very specific ones, such as the molecular transformation of organic compounds, to highly integrated ones, such as primary productivity. Positive BEF relationships arise from phenotypically- and genetically-based differences or trade-offs in species characteristics that drive the evolutionary diversification of niches (and the niches created by other species) through selective pressures, such that there is no single species or few species that perform(s) the different functions in exactly the same way or contribute(s) to all of the different functions (Turnbull et al., 2016). Consequently, it has been shown that the conservation of 
species diversity is necessary to sustain long-term functioning (GuerreroRamírez et al., 2017; Meyer et al., 2016; Reich et al., 2012) and multifunctionality of ecosystems (Allan et al., 2013; Hector and Bagchi, 2007; Isbell et al., 2011; Lefcheck et al., 2015; Meyer et al., 2018; Schuldt et al., 2018).

While BEF research has mostly focused on uncovering the links between species richness and ecosystem function, showing that some particular species or functional groups have a disproportionately strong contribution to BEF relationships, variation at different levels of ecological organization (genetic diversity, phylogenetic species diversity, functional diversity) can have comparable effects on ecosystem functioning (e.g., Hughes et al., 2008). In contrast to earlier assumptions (Cardinale et al., 2011), there seems to be low functional redundancy of coexisting species (Reich et al., 2012), particularly so across environmental contexts (Isbell et al., 2011), and therefore, at larger spatial scales that may cover more different environmental conditions (Isbell et al., 2017a). Thus, there is increasing awareness of the mechanistic links between traits involved in coexistence and resource use and traits affecting emerging properties and processes in ecosystems (Bannar-Martin et al., 2018; Chesson et al., 2001; Mori et al., 2018; Mouquet et al., 2002; Turnbull et al., 2013, 2016); although empirical evidence for the role of response and effect traits in ecosystem functioning still is limited (e.g., Beugnon et al., 2019; Paine et al., 2015; Yang et al., 2018).

\subsection{Identification of BEF mechanisms}

$\mathrm{BEF}$ research has identified a list of (non-mutually exclusive) mechanisms that contribute to enhancing ecosystem functioning with increasing biodiversity (e.g., increased biotope space describing the number of different ecological niches, more efficient resource use, multitrophic interactions, facilitation; Hooper et al., 2005; Weisser et al., 2017; reviewed by Barry et al., 2019a). Mathematical approaches and experimental treatments were established to disentangle different facets of biodiversity effects (e.g., complementarity effect, selection effect, and species asynchrony; Fox, 2005; de Mazancourt et al., 2013; Isbell et al., 2018; Loreau and Hector, 2001). More recent research has provided insights into niche dynamics. This means that species' realized niches change over time according to their competitive environment and their interaction network that are both dynamic in time and space (Hofstetter et al., 2007). As a consequence, this might lead to increasing biodiversity effects on certain ecosystem functions over time 
(Allan et al., 2011; Huang et al., 2018; Isbell et al., 2011; Lange et al., 2019; Meyer et al., 2016; Reich et al., 2012; Zuppinger-Dingley et al., 2014).

Previous studies, particularly short-term studies, may have underestimated the strength of biodiversity-ecosystem functioning relationships by missing these longer-term effects (Eisenhauer et al., 2012; Finn et al., 2013; Schmid et al., 2008). Among those is the important finding of strengthening complementarity effects (calculated based on Loreau and Hector, 2001) of species-rich communities over time (Cardinale et al., 2007; Huang et al., 2018; Reich et al., 2012; but see Kardol et al., 2018). These complementarity effects may be driven by several underlying mechanisms. For example, at low biodiversity, negative density-dependent effects of pests and pathogens may contribute to the deterioration of community functions in comparison to more diverse communities (Eisenhauer et al., 2012; Guerrero-Ramírez et al., 2017; Maron et al., 2011; Schnitzer et al., 2011; Schuldt et al., 2017b; Weisser et al., 2017). In contrast, species-rich communities may support more mutualistic interactions (e.g., Schuldt et al., 2017b; Wright et al., 2014), which may increase ecosystem functioning over time (Eisenhauer et al., 2012). These two mechanisms are not mutually exclusive (Guerrero-Ramírez et al., 2017), and different ecosystem functions show varying relative importance of the two mechanisms at the same time (Meyer et al., 2016). Despite these first promising insights into potential explanations of complementarity effects, the underlying ecological and evolutionary mechanisms remain elusive.

\subsection{BEF in multitrophic communities}

BEF research has demonstrated that biodiversity change at one trophic level cascades to other trophic levels. For example, plant diversity increases the diversity of above- and belowground consumer communities ("biodiversity begets biodiversity”; e.g., Ebeling et al., 2018; Eisenhauer et al., 2013; Haddad et al., 2009; Hines et al., 2019; Scherber et al., 2010; Thebault and Loreau, 2003), and independent biodiversity changes at more than one trophic level interactively affect ecosystem functions (e.g., Coulis et al., 2015; Eisenhauer et al., 2012; Gessner et al., 2010; Handa et al., 2014). Relatedly, it has been shown that complex, multitrophic communities affect the relationship between biodiversity and multiple ecosystem functions (Naeem et al., 1994; Schuldt et al., 2018; Soliveres et al., 2016a; van der Heijden et al., 1998; Wang et al., 2019). For instance, across a land-use intensity gradient in German grasslands, the diversity of primary producers, 
herbivorous insects, and microbial decomposers were particularly important predictors of plant biomass and forage quality (Soliveres et al., 2016a). For Chinese subtropical forests, it was shown that individual ecosystem functions central to energy and nutrient flows across trophic levels are more strongly related to the diversity of heterotrophs promoting decomposition and nutrient cycling, and affected by plant functional-trait diversity and composition, than by tree species richness (Schuldt et al., 2018). In managed Inner Mongolian grasslands, diversifying livestock by mixing both sheep and cattle promoted multidiversity (including the diversity of plants, insects, soil microbes, and nematodes) and multifunctionality (including plant biomass, insect abundance, nutrient cycling, and soil carbon) (Wang et al., 2019).

Perspectives papers have suggested to integrate BEF- and food-web theory to advance the understanding of causal relationships between complex communities and multiple ecosystem functions (Barnes et al., 2018; Duffy et al., 2007; Hines et al., 2015b, 2019; Thompson et al., 2012). Moreover, multitrophic interactions may play a decisive role in shaping BEF relationships via diversity-induced species plasticity in physiology, morphology, and micro-evolutionary processes (Mraja et al., 2011; Zuppinger-Dingley et al., 2014). However, even though one of the first biodiversity experiments manipulated multitrophic biodiversity in terrestrial ecotrons (Naeem et al., 1994), multitrophic BEF research in terrestrial ecosystems is still in its infancy, and the majority of existing studies focus on aquatic systems (Lefcheck et al., 2015; O'Connor et al., 2017; Seibold et al., 2018; Stachowicz et al., 2007, 2008a).

\subsection{BEF implications for ecosystem services}

Beyond its focus on ecosystem functioning, BEF research has also shown that biodiversity is important for a wide range of potential ecosystem services (Allan et al., 2015; Balvanera et al., 2006, 2014; Cardinale et al., 2012; Isbell et al., 2017a,b). These include provisioning, regulating, and also cultural services, underpinned by supporting services and includes, e.g., forage production (Binder et al., 2018; Finn et al., 2013), wood production (Isbell et al., 2017b), soil carbon storage for climate regulation (Fornara and Tilman, 2008; Lange et al., 2015), soil erosion control (Berendse et al., 2015; Pérès et al., 2013), water quality regulation (Scherer-Lorenzen et al., 2003), natural attenuation of pollutants in soil (Bandowe et al., 2019), pollination (Ebeling et al., 2008), and pest control (Hertzog et al., 2017) or herbivory reduction (Civitello et al., 2015; Schuldt et al., 2017b). 
Moreover, BEF research has stressed the role of multifunctionality, including the simultaneous provisioning of many functions at one location (e.g., Lefcheck et al., 2015; Schuldt et al., 2018) and across environmental contexts (Eisenhauer et al., 2018; Isbell et al., 2015a), as well as single functions in different settings (Isbell et al., 2011). However, this research has also highlighted that biodiversity does not necessarily enhance all ecosystem functions at the same time (Cardinale et al., 2012; van der Plas et al., 2016a,b), and trade-offs have been observed among different functions (Allan et al., 2015; Meyer et al., 2018). Moreover, studies simultaneously exploring a range of functions remain scarce, poorly represent the whole range of services provided by ecosystems, and are often disconnected from the utilitarian value of the (agro-)ecosystem (Manning et al., 2018; Swift et al., 2004; van der Plas et al., 2018). Nonetheless, these assessments of multifunctional ecosystems represent first important steps towards operationalizing BEF insights for society and policy makers (Manning et al., 2018) and will help to incorporate the importance of biodiversity for ecosystem-service provision in political discussions around the globe (including, e.g., halting biodiversity loss is included among sustainable development goals, changes to the European Common Agricultural Policy; IPBES reports, https://www.ipbes.net/).

\section{What are the key challenges of future BEF research?}

"The central problem in understanding and measuring biological diversity is that we still have a lot of work to do. And while we are taking inventory, the shelves are already being cleared."

Christian Wirth (2013)

Congruent to the statement above, biodiversity research is a field under time pressure. Biodiversity change can alter the functioning of ecosystems in dramatic ways and at an unprecedented pace, which will have important consequences for the provision of ecosystem services (Balvanera et al., 2006; Cardinale et al., 2012) and human health (Civitello et al., 2015; Lozupone et al., 2012; Wall et al., 2015). Some of the related key challenges of BEF research have been described in previous review papers (e.g., Cardinale et al., 2012; Hooper et al., 2005; Isbell et al., 2017a), and the plethora of (meta-)studies and mechanistic insights that were derived in the last years has helped to refine existing and ask novel questions in BEF research. Here, we argue that taking a multitrophic (Eisenhauer, 2017; Seibold et al., 2018) and eco-evolutionary perspective (Tilman and Snell-Rood, 2014; Zuppinger-Dingley et al., 2014) of biotic interactions will advance this field 
of research by identifying previously unknown mechanisms. Despite the broad consensus on the significance of BEF relationships, the underlying ecological and evolutionary mechanisms are not well understood, which impedes the transition from a description of patterns to a predictive science. Importantly, the focus should now not only be on generalizable patterns, but more on the context-dependency of BEF relationships (Baert et al., 2018; Craven et al., 2016; Eisenhauer et al., 2018; Fridley, 2002; GuerreroRamírez et al., 2017; Jousset et al., 2011; Kardol et al., 2018; Ratcliffe et al., 2017; Schuldt et al., 2017a). Understanding why and how the strength of biodiversity effects varies with environmental conditions and at which spatial scales different mechanisms operate will be key to operationalizing $\mathrm{BEF}$ insights for ecosystem management, society, and decision making. We will discuss these research frontiers in the following sections.

\subsection{Non-random biodiversity change across trophic levels}

"What escapes the eye... is a much more insidious kind of extinction: the extinction of ecological interactions."

Janzen (1974)

Real-world biodiversity change (both invasions and extinctions) can be highly non-random (Haddad et al., 2008; Wardle, 2016). Thus, future $\mathrm{BEF}$ research has to investigate how non-random biodiversity loss affects ecosystem functioning in real-world ecosystems (Isbell et al., 2017a,b). Addressing this question is particularly important in order to facilitate the application of BEF results to agriculture, forestry, and biodiversity conservation. At the same time, this is a very challenging task as biodiversity change and species turnover may be hard to predict due to multiple co-occurring and interacting global-change drivers (Scherber, 2015; Tylianakis et al., 2008) and their context-dependent effects on species and their interactions (Bowler et al., 2018; Schmid and Hector, 2004). Global change experiments, particularly those that manipulate multiple global change drivers, may be particularly valuable to study biodiversity changes and subsequent ecosystem responses (Giling et al., 2019; Vogel et al., 2019a). Furthermore, it might be promising to look more closely into the many published studies using random extinction scenarios, as some of them might by chance resemble extinction patterns that are actually observed in nature and provide opportunities for re-analysis (Manning et al., 2019). At the same time, the existing literature needs to be synthesized to derive a better understanding of trait-specific extinction risks of different taxonomic groups (Cardillo et al., 2005; Kotiaho et al., 2005; Seibold et al., 2015). 
Another aspect of non-random species loss that has attracted increasing scientific attention over the last years is the role of rare species for community functioning. Across ecosystems, the large majority of species are rare and thus prone to extinction (Jousset et al., 2017; Soliveres et al., 2016b; Suding et al., 2005). In contrast to the mass-ratio hypothesis, which assumes that locally abundant species drive ecosystem functioning (Grime, 1998), many studies have shown that rare species can have disproportionately strong impacts on ecosystems (Allan et al., 2013; Connolly et al., 2013; Klein et al., 2003; Lyons et al., 2005; Mouillot et al., 2013; Soliveres et al., 2016b). Future experiments thus need to investigate the role of rare species and their interactions with common species, and compare "realworld," non-random extinction scenarios with random extinction scenarios. Such an experiment was, for example, established in the subtropical BEF-China experiment, where two non-random extinction scenarios were included: one is based on local rarity and one on specific leaf area (SLA) of tree species, mimicking habitat loss through fragmentation and climate change, two current and likely future key drivers of change in Chinese subtropical forest communities (Bruelheide et al., 2014).

Both high trophic level and high body mass have been associated with vulnerability to extinction (with many related traits; Fig. 2; e.g., Dirzo et al., 2014; Voigt et al., 2003), but vulnerability to environmental change occurs at all trophic levels according to species' life history traits. Thus, the focus of previous terrestrial BEF experiments on manipulating the primary producer level does not necessarily reflect that this is the most vulnerable trophic level to environmental change. Although early BEF research already considered multiple trophic levels (e.g., Naeem and Li, 1997; Naeem et al., 1994), the understanding of how multitrophic communities change their diversity and how this affects their functioning in terrestrial ecosystems remains limited (Eisenhauer et al., 2013; Haddad et al., 2009; Scherber et al., 2010). Moreover, terrestrial BEF research so far has virtually neglected the fact that primary producers do not function in isolation, but in a complex network of multitrophic, and also non-trophic interactions (Fig. 2; Duffy, 2002; Hines et al., 2015b; Seabloom et al., 2017; Sobral et al., 2017; Tiede et al., 2016).

In complex food webs, the magnitude or rates of different ecosystem functions are tightly coupled to the community size structure describing how the body masses of species and individuals are distributed across trophic levels (Brose et al., 2017; Dossena et al., 2012). For instance, subtle shifts in the body mass structure of top consumer populations can induce strong trophic cascades with pronounced effects on primary production 


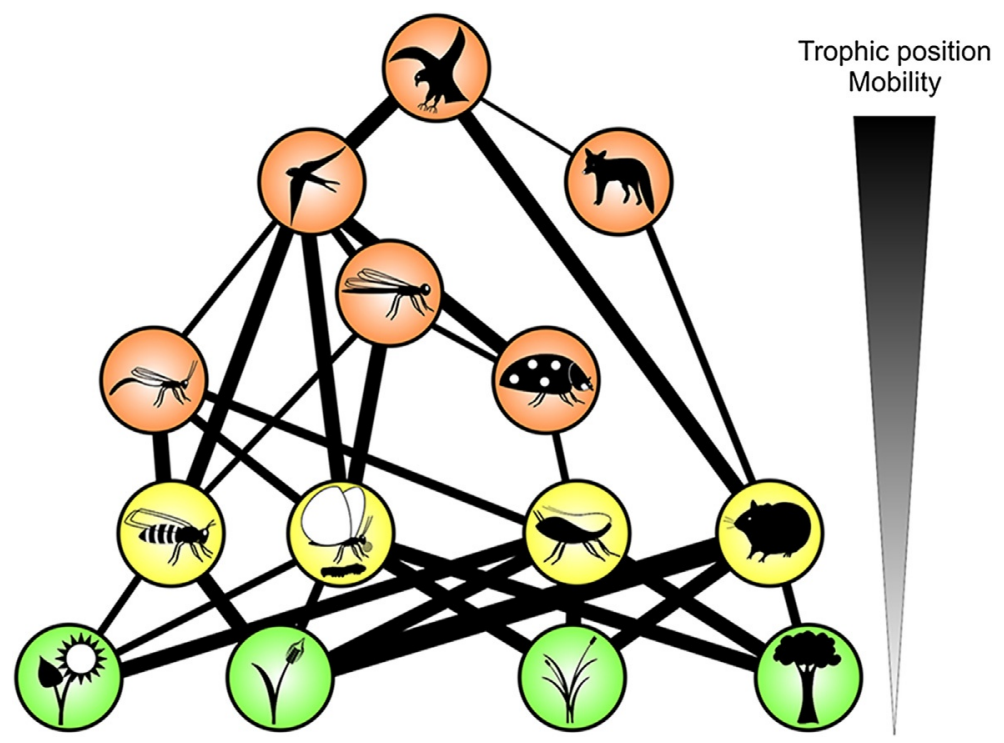

Fig. 2 A multitrophic perspective on biodiversity-ecosystem functioning research. Mobility tends to increase with increasing trophic position in ecological networks, and some work suggests that the vulnerability to environmental change does so, too (Hines et al., 2015a; Voigt et al., 2003), although species at all trophic levels may be vulnerable to changing environments based on their specific life-history traits. This means that the previous focus of BEF experiments on the primary producer level does not necessarily reflect that this is the most vulnerable trophic level to environmental change. This simple aboveground food web serves as the basis for other figures in this chapter. It illustrates that species within complex communities are connected by trophic links that can represent ecosystem functions and services (see also Fig. 3); although not shown here, the same concept applies to belowground food webs and ecosystem functions.

(Jochum et al., 2012). Consistently, analyses of complex food-web models demonstrated that primary production may be more tightly coupled to the trophic level and body mass of the top consumer than to total or plant diversity (Wang and Brose, 2018). Thus, ecological networks are an important tool that can be used to evaluate links that drive trade-offs between multiple ecosystem functions (Fig. 3; Brose et al., 2017; Hines et al., 2015b).

Across ecosystems, there is strong empirical evidence that the diversity at higher trophic levels is important for providing multiple ecosystem functions and services (Barnes et al., 2018; Bruno et al., 2006, 2008; Gessner et al., 2010; Hines et al., 2015b; Lefcheck et al., 2015; Schneider et al., 2012, 2016; Schuldt et al., 2018; Soliveres et al., 2016a; Wang et al., 2019). This was, for example, shown by manipulating stream-living macroinvertebrates and investigating their effect on decomposition (Cardinale et al., 2002; Handa 


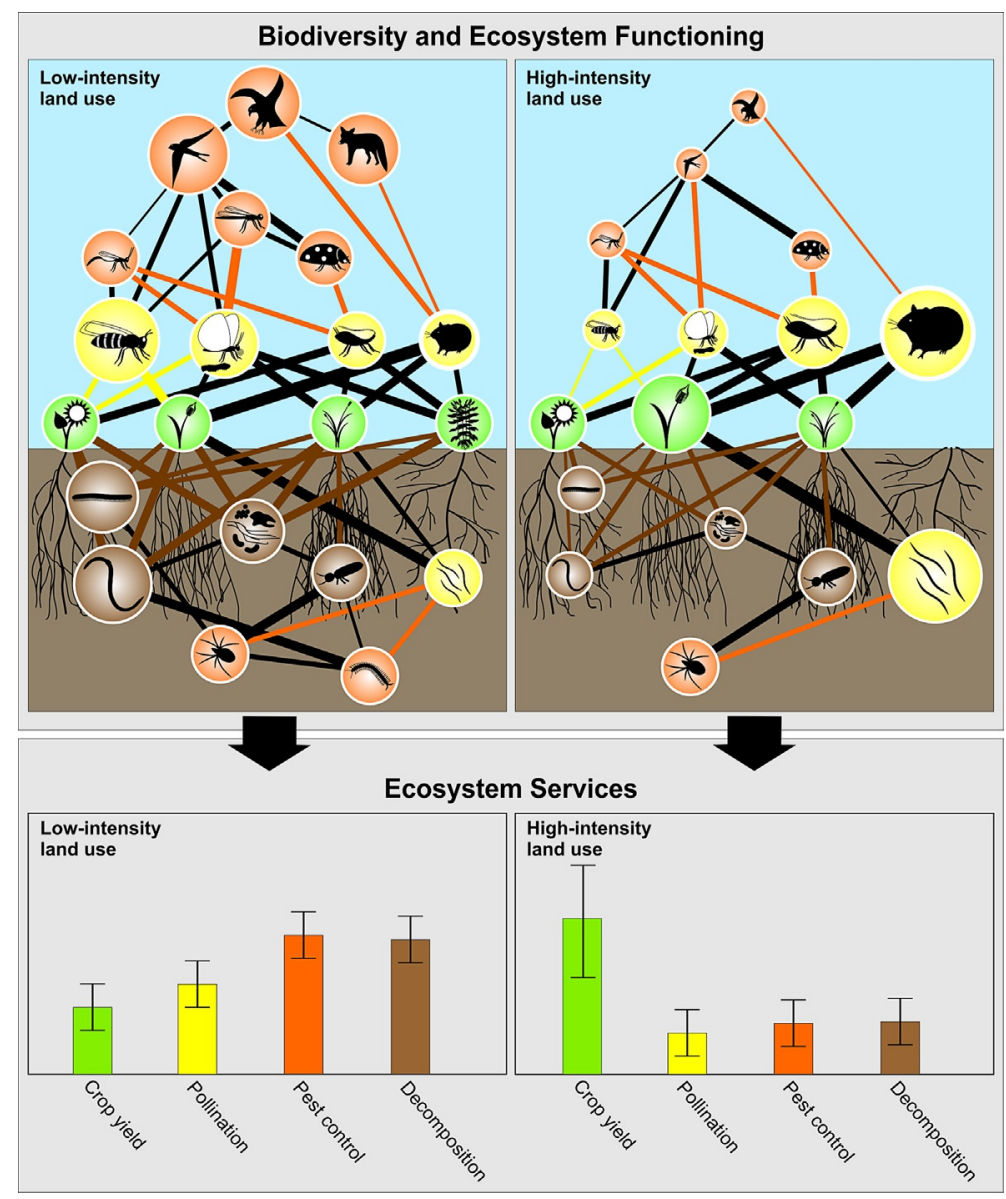

Fig. 3 Multitrophic communities drive ecosystem multifunctionality. This scheme depicts relationships between the diversity of species in aboveground-belowground networks and the management of multiple ecosystem services across adjacent agricultural ecosystems. Management decisions, such as intensifying agricultural practices (right part of the figure), that focus on locally maximizing one ecosystem service, such as crop yield, can limit the other ecosystem services provided in complex food webs in a given area (e.g., pest control is reduced, indicated by higher biomass of aphid and vole). Note that the stability of delivering the focal service decreases in this example (larger error bar in crop yield) at high land-use intensity (Isbell et al., 2017b). Socio-political context related to human population density and stakeholder interests can influence feedbacks between ecosystem services and the management of complex ecosystems. Importantly, ecosystem services are not solely provided by single nodes in the food web and at a single location, but by the interaction among multiple nodes (colours of example links between nodes in upper part, correspond to ecosystem service bar colours in lower part) across adjacent ecosystems. Redrawn after Hines et al., 2015 b. 
et al., 2014), or by manipulating the diversity of aphid natural enemies and investigating pest control (Cardinale et al., 2003). Biodiversity changes at higher trophic levels of aquatic ecosystems have been shown to exert cascading effects on the biomass production at lower levels (Duffy et al., 2007; Worm and Duffy, 2003). This finding was generalized by models of complex food webs, in which increased animal diversity led not only to higher herbivory but also, counter-intuitively, to higher primary production by plants (Schneider et al., 2016). This surprising finding is explained by systematic trait shifts in the plant communities that are induced by the increased top-down pressure (Schneider et al., 2016). These results contribute to the general notion that biodiversity changes across trophic levels can have complex indirect effects, which strongly calls for a multitrophic whole-ecosystem perspective for mechanistically understanding BEF relationships (Barnes et al., 2018; Brose and Hillebrand, 2016; Eisenhauer, 2017; Hines et al., 2015b; Seibold et al., 2018; Thompson et al., 2012; Worm and Duffy, 2003).

Ultimately, the understanding of real-world BEF relationships requires coupling multitrophic biodiversity change and indirect effects among species addressed at local habitat scales with spatio-temporal upscaling to the landscape level. However, research on multitrophic interactions and quantitative food-web changes in space and time is little developed so far (but see, e.g., Grass et al., 2018; Tscharntke et al., 2012). Across ecosystems, the increase in the number of interactions between species is predictably linked to the simultaneous increase in the number of species (Brose et al., 2004). This connection between species-area and link-area relationships facilitates the prediction of food-web complexity at the landscape level, but upscaling of BEF relationships would also require integrating the identities or traits of species and their interactions into models. In this vein, behavior- and trait-based allometric random walk models (Hirt et al., 2018), as well as extensions of the classic theory of island biogeography that account for effects of the species' trophic levels (Gravel et al., 2011), body masses (Jacquet et al., 2017), and network-area relationships (Galiana et al., 2018), have great potential to become important cornerstones of novel BEF upscaling approaches (see also section "Spatial scaling of BEF relationships").

In order to account for the finding of substantial species turnover and biotic homogenization due to human activities (Dornelas et al., 2014; Gossner et al., 2016), future BEF experiments may also include both species gains and losses (Mori et al., 2018; Wardle et al., 2011) across different trophic levels. Integrating trophic complexity will be key to account for cascading, facilitative, and competitive effects in order to understand how 
biodiversity affects whole-ecosystem functioning (Barnes et al., 2018), regardless of the direction of biodiversity change (loss or gain; Wardle, 2016). Moreover, biotic homogenization across trophic levels may have important implications for the stable provisioning of multiple ecosystem services (Hautier et al., 2018; Pasari et al., 2013; van der Plas et al., 2016a,b) as synchrony in responses across species may compromise ecosystem functioning (Craven et al., 2018; de Mazancourt et al., 2013). Higher synchrony among species in space and time may be particularly deleterious for ecosystems with ongoing global change as predicted by the temporal and spatial insurance hypotheses of biodiversity (Loreau et al., 2003a; Yachi and Loreau, 1999).

The explicit quantification of fluxes of energy and matter in BEF experiments would greatly facilitate the integration of different trophic levels (Barnes et al., 2014, 2018; Lindeman, 1942; Stocker et al., 1999; Wilsey and Polley, 2004). Flux rates may be more sensitive and may show faster responses to variations in biodiversity than pools (Meyer et al., 2016; but see Liu et al., 2018 for a counter example). Evidence for this, however, is scarce (but see Allan et al., 2013; Niklaus et al., 2016), but this deserves further attention, particularly in long-term (Huang et al., 2018; Meyer et al., 2016) and multitrophic experiments (Eisenhauer, 2017). An Ecotron study with intact soil monoliths from the Jena Experiment (Milcu et al., 2014) under controlled conditions allowed for the quantification of the effects of plant diversity on ecosystem carbon fluxes and uptake efficiency of plants. Indeed, it was observed that increasing plant species and functional diversity led to higher gross and net ecosystem carbon uptake rates, and effects were partly mediated by the leaf area index and the diversity of leaf nitrogen concentrations of the plant community (Milcu et al., 2014). While the consideration of multitrophic interaction partners in such studies is still in its infancy, new research infrastructures have been established to explore the role of above- and belowground food webs in fluxes of energy and matter (Eisenhauer and Türke, 2018).

Assessing energy flux dynamics in ecological networks provides the mechanistic underpinning of multitrophic BEF relationships, which is why the quantification of energy fluxes in food webs may be a powerful tool for studying ecosystem functioning in multitrophic systems ranging from biodiversity experiments to real-world ecosystems (Barnes et al., 2018). By combining food-web theory with BEF theory (Hines et al., 2015b), whole community energy-flux assessment enables investigators to quantify many different types of multitrophic ecosystem processes without having to 
measure them all separately (Barnes et al., 2018). Energy flux can then be used as an integrated measure and a common currency to compare certain types of processes (e.g., herbivory or predation) across different ecosystem types (Barnes et al., 2018); however, energy-flux calculations need to be validated by actual process measurements (e.g., Schwarz et al., 2017), which in complex ecosystems such as grasslands and forests poses a serious challenge.

\subsection{Predicting the strength of BEF relationships across environmental contexts}

"The idea that the mechanisms underpinning species coexistence are the same as those that link biodiversity with ecosystem functioning can be traced all the way back to Darwin's principle of divergence..."

Turnbull et al. (2013)

The strength and sign of BEF relationships have been reported to differ among studies as well as among biotic and environmental contexts (e.g., Baert et al., 2018; Fridley, 2002; Guerrero-Ramírez et al., 2017; Jousset et al., 2011; Jucker et al., 2016; Kardol et al., 2018; Ratcliffe et al., 2017; Steudel et al., 2012; but see Craven et al., 2016). We still have scant knowledge about how and why effects of the diversity and composition of communities on ecosystem functions vary. How context-dependent are BEF relationships, and what biotic and abiotic factors drive this context-dependency?

There have been several empirical attempts to study BEF relationships under different environmental contexts, such as the BIODEPTH experiment across eight European countries (Hector et al., 1999), the COST Agrodiversity experimental network across 31 sites in Europe and Canada (Finn et al., 2013; Kirwan et al., 2007), the global network of tree diversity experiments in TreeDivNet (Grossman et al., 2018; Paquette et al., 2018), the global Nutrient Network (Borer et al., 2014, 2017), the global metaanalyses in drylands (Maestre et al., 2012) and forests (Guerrero-Ramírez et al., 2017), the BioCON experiment in Cedar Creek studying effects of elevated $\mathrm{CO}_{2}$ concentrations and $\mathrm{N}$ deposition (Reich et al., 2001), the BAC experiment in Cedar Creek exploring warming effects (Cowles et al., 2016; Pennekamp et al., 2018; Thakur et al., 2017), the two sites of the BEF-China experiment (Huang et al., 2018), and the Jena drought experiment (Vogel et al., 2012). Moreover, in the Jena Experiment (Roscher et al., 2004), researchers have applied a large number of subplot treatments to study if plant diversity effects are contingent upon management intensity (Weigelt et al., 2009), above- and belowground consumers (Eisenhauer et al., 2011), and plant invasion (Petermann et al., 2010; 
Roscher et al., 2009; Steinauer et al., 2016). Although some studies report $\mathrm{BEF}$ relationships in plant diversity experiments to be consistent across abiotic and biotic contexts (e.g., Craven et al., 2016; O'Connor et al., 2017; Thakur et al., 2015), there is substantial variability within and across studies depending on the point in time of the measurement (Kardol et al., 2018; Reich et al., 2012; Wright et al., 2015), the biodiversity facet investigated (Craven et al., 2016), and the trophic level and complexity of the studied community (Beugnon et al., 2019; Mulder et al., 1999; O'Connor et al., 2017; Seabloom et al., 2017).

In response to some of the initial debates regarding the validity of BEF relationships across environmental contexts (e.g., Givnish, 1994; Tilman and Downing, 1994), previous BEF research focused heavily on completely removing any "confounding" effects of abundance, biomass, and environmental gradients, in order to isolate and quantify "true" biodiversity effects. It is, however, important to understand biodiversity effects in the context of other co-varying factors to better predict scenarios of ecosystem function given species gains or losses (which covary with many other factors; Wardle, 2016). Future research should thus aim at understanding the functional role of biodiversity in dynamic ecosystems that are not at competitive equilibrium (Brose and Hillebrand, 2016; Leibold et al., 2004) as well as in affecting multiple dimensions of stability under changing environmental conditions (Donohue et al., 2016; Pennekamp et al., 2018). Such information is, for instance, urgently needed to inform predictive BEF models and to provide tailored management recommendations that account for local environmental conditions (Guerrero-Ramírez et al., 2017).

Conceptual advances are likely to be achieved by utilizing niche and coexistence theory to understand the context-dependency of BEF relationships (Barry et al., 2019; Turnbull et al., 2016). Environmental change often affects the composition of communities by altering the environmental conditions, modifying available niche space directly (niche destruction; Harpole et al., 2016) and/or indirectly through altered biotic interactions (Turnbull et al., 2016). For instance, the addition of nutrients has been repeatedly shown to favour the growth of certain plant species with high nutritional demands and fast uptake strategies (Clark et al., 2007; Harpole and Tilman, 2007; Harpole et al., 2016; Vogel et al., 2019a). Increased plant growth of some species, in turn, induces the shading of other species, which then disappear because their niche requirements are no longer met (Hautier et al., 2009). The resulting loss of species then undermines ecosystem functions of the depauperate plant communities (Isbell et al., 2013). 
The same mechanisms that permit the coexistence of different species, namely niche differences, also are the key for the complementary resource use and resultant overyielding (Barry et al., 2019c; Loreau, 2004; Tilman et al., 1997b; Turnbull et al., 2013, 2016; Vandermeer, 1981) and transfer of energy across trophic levels (Barnes et al., 2014). Niche differentiation and facilitation within (Cardinale et al., 2007; Reich et al., 2012; Wright et al., 2017) and across trophic levels (Ferlian et al., 2018; Poisot et al., 2013) are often found to be the main mechanisms behind positive BEF relationships. As a consequence, changes of the environmental conditions that influence the co-existence of species are also likely to affect the strength of BEF relationships (Barry et al., 2019b). In support of this notion, positive BEF relationships have been shown to be strongest in complex resource environments (Fig. 4) and to become non-significant or even negative in homogenous resource environments (Eisenhauer et al., 2013; Hodapp et al., 2016; Jousset et al., 2011; Mouquet et al., 2002; Norberg et al., 2001). Hodapp et al. (2016) generalized this to resource supply heterogeneity landscapes and showed that strongly positive effects of richness on ecosystem function occur only if (1) species differ in traits, (2) environments show heterogeneity, and (3) dispersal allows effective species sorting. Research on algal model communities in relatively structured environments (flow habitats and disturbance regimes) has shown that communities with more species take greater advantage of the niche opportunities in a given environment, and this allows diverse systems to better perform ecosystem functions (Cardinale, 2011; Stachowicz et al., 2007, 2008a). Taken together, these results indicate that environmental heterogeneity promotes complementarity effects (see, e.g., Wacker et al., 2008) and thus steeper BEF relationships (Fig. 4), suggesting that habitat homogenization may compromise positive biodiversity effects on ecosystems.

To study the context-dependence of BEF relationships, different sitespecific conditions for biodiversity effects, including environmental stress and resource availability (Fig. 4), will need to be disentangled (Baert et al., 2018; Guerrero-Ramírez et al., 2017). Global networks of experiments using standardized methods (Grossman et al., 2018; Lefcheck et al., 2016; Meyer et al., 2015) and syntheses of data are needed and have proven to be extremely powerful in detecting global biodiversity(-function) patterns and underlying mechanisms (e.g., Nutrient Network; Borer et al., 2014, 2017; Grace et al., 2016). Notably, such standardized assessments are particularly important for quantifying multitrophic interactions across environmental gradients (Kambach et al., 2016; Roslin et al., 2017) that are 

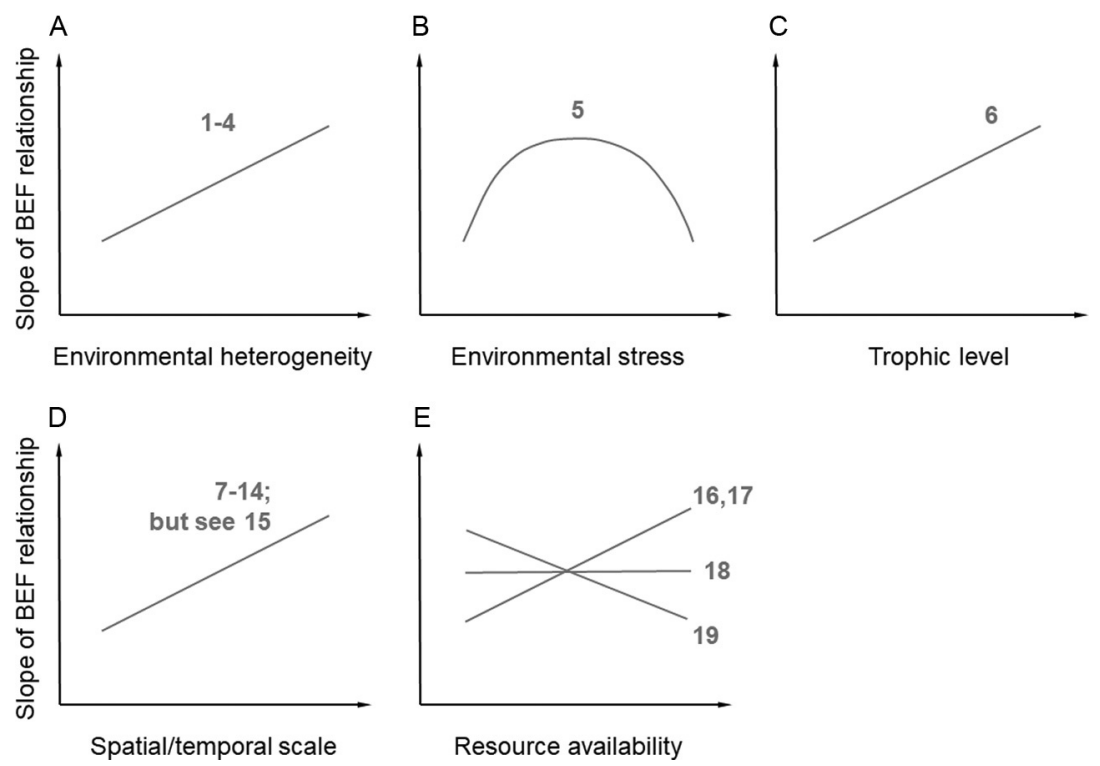

Fig. 4 Context-dependent biodiversity-ecosystem functioning (BEF) relationships; examples include (A) environmental heterogeneity, (B) environmental stress, (C) trophic level, (D) spatial and temporal scale, and (E) resource availability. Although the proposed relationships are supported by some studies (examples given, no comprehensive list of studies), a thorough understanding of the context-dependency of BEF and the underlying mechanisms is elusive. Thus, the depicted relationships should be regarded as working hypotheses for future research. See also Bardgett and Wardle (2010) (Fig. 5.3 and references therein) for a similar conceptualization of the context-dependency of BEF relationships that are mostly based on observational studies and removal experiments, rather than on random biodiversity manipulation experiments, as done here. For panel (B), we followed the definition by Chase and Leibold (2003), stating that "stressful niche factors limit the per capita population growth rate of the focal population, but are not influenced by changes in the population size." 1 : Stachowicz et al. (2008b), 2: Griffin et al. (2009), 3: Cardinale (2011), 4: Jousset et al. (2011), 5: Baert et al. (2018), 6: Lefcheck et al. (2015), 7: Cardinale et al. (2007), 8: Eisenhauer et al. (2010), 9: Cardinale et al. (2011), 10: Isbell et al. (2011), 11: Reich et al. (2012), 12: Thakur et al. (2015), 13: Meyer et al. (2016), 14: Guerrero-Ramírez et al. (2017), 15: Kardol et al. (2018), 16: Reich et al. (2001), 17: Fridley (2002), 18: Craven et al. (2016), 19: Zhang and Zhang (2006).

intimately linked with ecosystem function (Eisenhauer et al., 2019). For instance, different tree diversity experiments around the globe collaborate in the framework of TreeDivNet (Paquette et al., 2018; Verheyen et al., 2016) and allow for countering criticisms related to realism, generality, and lack of mechanistic explanation in their work (Grossman et al., 2018; Paquette et al., 2018). However, empirical work and syntheses should 
not be restricted to certain ecosystems, but should span across ecosystem types (e.g., aquatic and terrestrial; Balvanera et al., 2006; Cardinale et al., 2011; Handa et al., 2014; Lefcheck et al., 2015; Ruiz-González et al., 2018; Schuldt et al., 2019). Recent modelling (e.g., Baert et al., 2018) and empirical work (e.g., Guerrero-Ramírez et al., 2017) provided exciting working hypotheses for future research (Fig. 4).

\subsection{Spatial scaling of BEF relationships}

"Biodiversity loss substantially diminishes several ecosystem services by altering ecosystem functioning and stability, especially at the large temporal and spatial scales that are most relevant for policy and conservation."

Isbell et al. (2017a)

To date, BEF relationships have mostly been investigated at small scales (e.g., in microcosms, mesocosms, or small plots; Cardinale et al., 2011), raising the question "How does the BEF relationship change with spatial scale?" (Barnes et al., 2016; Isbell et al., 2017a; Manning et al., 2019; Thompson et al., 2018). Accordingly, Mori et al. (2018) recently stressed the need for unification of beta-diversity and among-patch ecosystem-function theory. The focus on small-scale studies may also be one reason for described mismatches between local-scale observational and experimental BEF studies and conclusions drawn for management-relevant scales in non-experimental settings (Oehri et al., 2017; van der Plas et al., 2016a,b). Thus, future research needs to bridge the gap between results from local-scale BEF experiments and real-world relevant scales in order to understand whether and how biodiversity effects are important at the landscape scale (Cardinale et al., 2012; Isbell et al., 2017a; Thompson et al., 2018). There is empirical evidence suggesting that the importance of biodiversity in driving ecosystem functions increases as more spatial contexts, i.e., different environmental conditions, are considered (Grace et al., 2016; Hautier et al., 2018; Isbell et al., 2011; Mori et al., 2016; Thompson et al., 2018), stressing the role of environmental heterogeneity in driving the strength and mechanisms of BEF relationships (Cardinale, 2011; Griffin et al., 2009). One solution may be the development of spatial upscaling algorithms to relate local BEF findings to patterns at the landscape scale. Using such an approach, Barnes et al. (2016), however, showed that the relative importance of biodiversity for ecosystem functions decreased with increasing spatial scale. Such contradicting findings are also observed in fragmentation-biodiversity studies when focusing on patches or landscapes (Fahrig et al., 2019), and 
integrating the ecosystem function aspect in fragmentation studies may help bridging this field of research to BEF (Fahrig, 2017). Hence, the mechanisms dominating biodiversity and functions might differ between small and large spatial scales (Loreau et al., 2003a,b). This indicates the need for future research on this topic, particularly if we are to integrate knowledge from BEF experiments in ecosystem service modelling and other spatial mapping exercises.

While BEF experiments have been "stuck" in plots and buckets, metacommunity theory has been dealing with species appearance and disappearance without an explicit link to ecosystem functioning (Bannar-Martin et al., 2018; Leibold and Chase, 2018; Leibold et al., 2004, 2017; but see Loreau et al., 2003b). Thus, species pools and their turnover and dynamics need to be incorporated into BEF research (Bannar-Martin et al., 2018; Wardle, 2016) to consider the links between community assembly/coexistence mechanisms (e.g., dispersal, demographic stochasticity, niches/traits) and ecosystem functioning (Hillebrand et al., 2018). One step towards this goal may be to identify trade-offs in spatial and temporal scales at which diversity maximizes single and multiple ecosystem functions. In fact, considering multitrophic consumer networks that link different landscape patches and ecosystem compartments through the flux of energy across trophic levels (Barnes et al., 2014) might be a promising approach to facilitate the upscaling of local processes to landscape-level function (Fig. 5; Barnes et al., 2018). For instance, future research efforts on land-use change and restoration could be targeted towards manipulating biodiversity at different spatial scales and exploring whole-ecosystem consequences within and across different patches and compartments. Another option are disturbances acting at the landscape scale. They offer excellent options for BEF studies at larger spatial scales, but research plans have to be made long before such disturbances happen (Lindenmayer et al., 2010).

Dispersal may promote the functioning of ecosystems in two ways (Leibold et al., 2017; Loreau et al., 2003a; Thompson and Gonzalez, 2016). First, species dispersal and community assembly processes may allow species to track local environmental changes by shifting in space, which may then preserve biodiversity and ensure high ecosystem functioning (Leibold et al., 2017; Loreau et al., 2003a; Thompson and Gonzalez, 2016). Second, source-sink dynamics may allow species to persist in suboptimal environments, thus increasing local biodiversity over time, although this does not necessarily promote functioning (Leibold et al., 2017). Species-sorting dynamics also provide spatial insurance, so that compensatory dynamics 


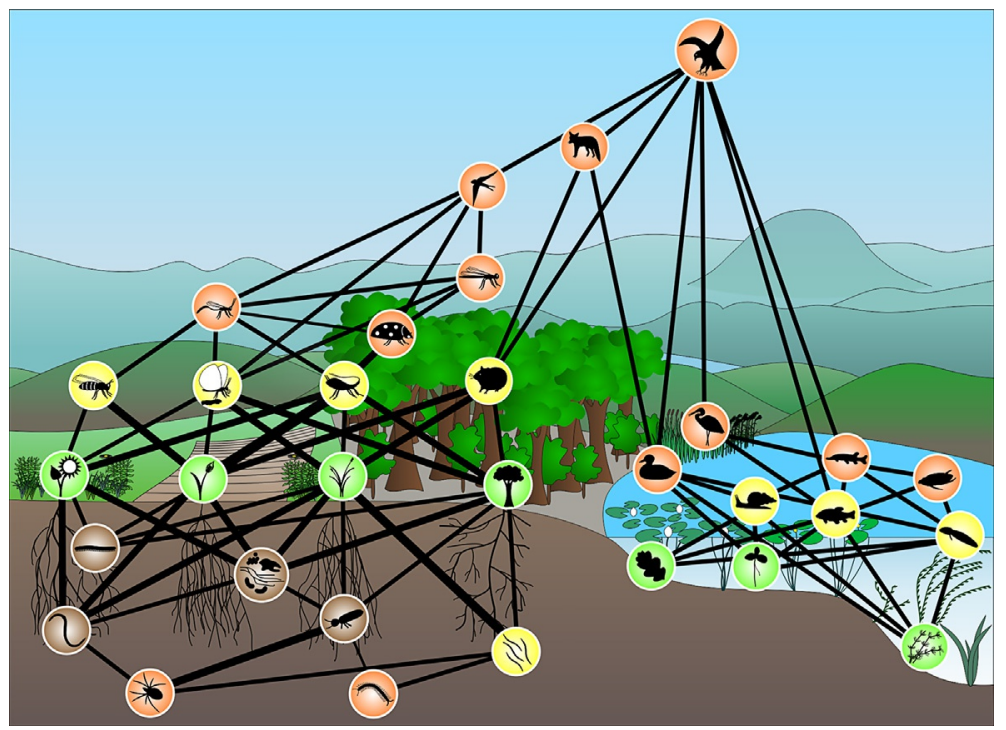

Fig. 5 Complex communities link different habitats, a consideration that may facilitate the upscaling of BEF. Conceptual illustration of how multitrophic interactions across ecosystem boundaries can link different ecosystem types and compartments, including above- and belowground compartments, forests and grasslands, as well as terrestrial and aquatic ecosystems. Links between different network modules in these subsystems provide stability of trophic dynamics, matter and energy flow across system boundaries as well as stability of ecosystem function and service delivery (Barnes et al., 2018).

stabilize the fluctuations of each function through time at the regional, but not necessarily at the local scale (Loreau et al., 2003a; Thompson and Gonzalez, 2016). Relatedly, spatial network modularity has a buffering effect in perturbed experimental metapopulations, protecting some local subpopulations from the perturbation (Gilarranz et al., 2017) or providing empty patches for recolonization, ultimately stabilizing the metapopulation (Fox et al., 2017). Adding to this complex picture, there is experimental evidence suggesting that also habitat isolation and matrix quality influence biodiversity and ecosystem functioning (Spiesman et al., 2018). Thus, the fragmentation and connectivity of habitat patches as well as the mobility of taxa driving meta-community dynamics are likely to be of great importance, yet understudied in BEF research (Gonzalez et al., 2017).

Most terrestrial ecosystems have soft boundaries that are highly permeable for many species. Accordingly, different ecosystems should not be regarded in isolation but in the context of surrounding ecosystems. For instance, biodiversity effects on adjacent ecosystems should be studied to 
explore the links between ecosystems (e.g., by linking aquatic ecosystems, forests, agricultural fields, etc.) and the role of "source" and "sink" dynamics in fluxes of elements, energy, organisms, biomass, and information between adjacent ecosystems (Gounand et al., 2018; Knight et al., 2005). Here, the investigation of key organisms linking different ecosystems may be particularly relevant to move from the plot scale to the landscape scale (Barnes et al., 2018; Fig. 5) as well as to define conservation priorities and corresponding management practices.

\subsection{Eco-evolutionary implications of multitrophic BEF}

"Nothing in evolution or ecology makes sense except in the light of the other."

Pelletier et al. (2009)

Ecology and evolution are sometimes thought of as acting at different timescales, which might explain why evolutionary processes have rarely been considered in past BEF research. However, a growing body of literature shows that evolutionary processes can be rapid and of relevance at what is commonly considered ecological timescales (Carroll et al., 2007; Hendry, 2016), such that a strict time-scale separation is no longer useful. Furthermore, the study of the molecular basis of adaptation has experienced a boost due to recent technological developments (Bosse et al., 2017; Savolainen et al., 2013; Stapley et al., 2010; Wuest and Niklaus, 2018). BEF research may greatly benefit from embracing the rich and growing body of knowledge on micro-evolutionary processes, population genetics, and the molecular basis of adaptation, because adaptation and evolutionary processes are likely to contribute to the dynamic nature of BEF relationships (e.g., Tilman and Snell-Rood, 2014; van Moorsel et al., 2018; ZuppingerDingley et al., 2014). Such eco-evolutionary processes can ideally be studied in the few long-term experiments worldwide that have been run for multiple generations of the organisms studied.

Undoubtedly, members of an ecological community impose selection pressures onto each other. For example, changing phenotypes have been reported in a number of plant species in response to manipulated biodiversity gradients (Lipowsky et al., 2011, 2012; Schöb et al., 2018; ZuppingerDingley et al., 2014, 2016). Phenotypic changes may allow different coexisting species to use resources in more dissimilar and complementary ways, thereby reducing competition, maximizing growth, and favouring stable coexistence (Tilman and Snell-Rood, 2014; Zuppinger-Dingley et al., 2014). Yet, we know too little about the relative importance of 
phenotypic plasticity, transgenerational epigenetic processes (Schmid et al., 2018), and genuine evolutionary adaptation that simultaneously contribute to phenotypic changes (Hoffmann and Sgrò, 2011; Zuppinger-Dingley et al., 2014). Such knowledge is important, however, in order to estimate how lasting and/or reversible the effects are.

There are a number of ways in which micro-evolutionary processes may help to understand and predict BEF relationships. For example, a significant role of the comparatively slow process of evolutionary adaptation may explain the observation of strengthening BEF relationships over time in grassland experiments (Tilman and Snell-Rood, 2014; Vogel et al., 2019b; Zuppinger-Dingley et al., 2014). Furthermore, micro-evolutionary dynamics may lead to positive feedback loops that can affect ecosystem functioning. Natural selection is usually expected to reduce genetic variance, but genetic variation provides the raw material for future adaptation (Mousseau and Roff, 1987). Frequent changes in the selective regime may thus jeopardize populations' persistence (Hoffmann and Sgrò, 2011). Phenotypic plasticity, in contrast, may buffer populations against changing selection regimes (Charmantier et al., 2008). Taking into account the relative importance of phenotypic plasticity and micro-evolutionary adaptation will be essential for the understanding of how adaptation processes affect BEF relationships.

Members of a community mutually influence each other during the selection process (Jousset et al., 2016; Tilman and Snell-Rood, 2014). Two aspects seem to be particularly relevant in the context of community assembly. First, functionally similar and/or related species will be selected for character displacement and niche differentiation, thereby promoting specialization, coexistence, and ecosystem processes (Harmon et al., 2009; Tilman and Snell-Rood, 2014). The genetic and evolutionary mechanisms of such processes have rarely been studied in BEF research. Second, species may co-evolve together with their antagonists, e.g., pathogens (Vogel et al., 2019b). Here, the species involved can differ substantially in generation time. Pathogens may adapt and change quickly, imposing persistent and likely fluctuating selection pressure on host species. Indeed, several studies showed that negative plant-soil feedback effects can induce a decrease in plant growth in monoculture (e.g., Hendriks et al., 2013; Maron et al., 2011; Schnitzer et al., 2011). Deteriorating monocultures over time indicates that Janzen-Connell effects, the accumulation of species-specific plant antagonists, may play an important role in BEF relationships (Petermann et al., 2008). Zuppinger-Dingley et al. (2014) proposed that a respective selection pressure should be particularly pronounced in low-diversity plant 
communities (see also van Moorsel et al., 2018). In contrast, accumulation of such species-specific plant antagonists in high-diversity plant communities would be impeded because of lower host densities (Civitello et al., 2015; Hantsch et al., 2013, 2014; Rottstock et al., 2014). On the other hand, prolonged time in monocultures in the Jena Experiment has converted negative into positive net plant-soil feedback effects (Zuppinger-Dingley et al., 2016), which could be partly due to evolved resistance of the plants and/or a slower build-up of communities of mutualists like the accumulation of plant growth promoting rhizobacteria (Latz et al., 2012) in comparison to antagonists. Taken together, these lines of evidence suggest that dissimilar host-pathogen interactions at low versus high biodiversity may impose different selection pressures on community members, both at the level of plant species and genotypes (Roscher et al., 2007).

Genetic diversity within species offers the raw material for future adaptations (Jousset et al., 2016), even if some of the variation may not be utilized under current conditions (Paaby and Rockman, 2014). Genetic variation, thus, serves as a genetic insurance for population persistence and ultimately for sustained ecosystem functioning. It is vital to understand the processes that affect intra-specific diversity in communities differing in species diversity (Vellend and Geber, 2005). Genetic diversity depends on the effective population size, which in turn is determined by census size, reproductive system, spatial structure, and the intensity and shape of natural selection. Strong directional and stabilizing selection both tend to reduce genetic diversity. The potential cascading effects of community diversity on population diversity and eventually intra-specific and phylogenetic diversity as well as consequences for ecosystem functioning are poorly studied (but see Crutsinger et al., 2006; Hughes et al., 2008; Zeng et al., 2017). In fact, there has been a recent interest in how populations assemble with respect to functional diversity, but also phylogenetic diversity, and the underlying mechanisms are relevant in the BEF context as community assembly and disassembly processes have implications for the long-term functioning of plant communities (Vogel et al., 2019a). Species differ partly due to divergent directional selection. Under the premise that phylogenetic distance contains a signal of divergent selection for (unknown) functional traits, phylogenetic distance can be used as a proxy for functional diversity (Cadotte et al., 2008; Vogel et al., 2019a). However, such genetic conservatism may be highly variable among traits, for instance among leaf and root traits of plants (e.g., Valverde-Barrantes et al., 2017). Therefore a combination of traits and stepwise phylogeny has been proposed (Cadotte, 2013) and successfully 
applied in multitaxon studies (Thorn et al., 2016). Translating these challenges that have mostly been addressed for herbaceous plants to higher trophic levels, it is also relevant to explore how much phylogenetic diversity is represented within multitrophic communities for applied conservation aspects (Eisenhauer et al., 2019).

The field of ecological genetics has seen a great expansion in opportunities by the rapid development of next-generation sequencing technologies (Savolainen et al., 2013). It is now possible to sequence and assemble the genome of just about any species at manageable cost, which allows the study of the genomics of previous non-model organisms in natural conditions (Ellegren, 2014; Savolainen et al., 2013; Stapley et al., 2010). Genotyping-by-sequencing techniques allow the study of genetic polymorphisms without much cost- and labor-intensive development of genetic markers and gives an unbiased view on population-wide genetic diversity (Narum et al., 2013). There are many ways how these new technologies can be employed in a BEF context. A particularly exciting avenue is the study of co-evolutionary dynamics in multi-species systems up to the community level. Genomic and transcriptomic methods may allow to uncover the genetic architecture of functional trait variation (Schielzeth and Husby, 2014). Moreover, population genomics allows studying the population structure and inbreeding patterns at high resolution across multiple species. Ultimately, such knowledge will help to link the diversity at the genome level to ecosystem-level processes (Wuest and Niklaus, 2018) and to explore the role of species interactions driving these interlinkages.

\subsection{FAIR data and beyond}

"The grand challenge for biodiversity informatics is to develop an infrastructure to allow the available data to be brought into a coordinated coupled modelling environment able to address questions relating to our use of the natural environment that captures the variety, distinctiveness and complexity of all life on Earth."

Hardisty and Roberts (2013)

Data plays an increasingly important role for BEF research (Trogisch et al., 2017). As for other subdisciplines of biodiversity research, this results in a need for improved biodiversity informatics along all steps of the data lifecycle from data collection to data analysis and publication (Hardisty and Roberts, 2013). Due to the availability of novel methods like highthroughput sequencing, automatic monitoring, and remote sensing, more and more data are being produced in BEF research. Thus, the resulting data are likely to play an important role in future BEF research, as 
high-throughput sequencing has the potential to help identifying potential microbial drivers of BEF relationships (e.g., Laforest-Lapointe et al., 2017), automatic monitoring may be key to link behavioural ecology of animals to multitrophic BEF (e.g., Dell et al., 2014; Eisenhauer and Türke, 2018), and remote sensing is likely to help scaling up BEF research to the landscape scale (e.g., Cabello et al., 2012). Often, the amount of such data collected exceeds available resources for manual processing. Recently established methods in machine learning, in particular deep neural networks, have the potential to alleviate this problem (see Brust et al., 2018 and Ryo and Rillig, 2017 for successful examples). Currently, however, the applicability of these methods is restricted by their need for large sets of labelled training data. Further development of methods to reduce the need for training data and/or semi-automatically label data are needed. Additionally, better tools for data quality assurance and improvement are needed, such as comprehensive data quality frameworks (Morris et al., 2018; Veiga et al., 2017). These are not yet part of commonly used data management platforms though.

Answering important questions in BEF research often requires data that covers large temporal and spatial scales. Few projects run long enough or cover a wide enough geographical range to be able to collect all the data needed themselves. Thus, BEF research relies on data reuse and sharingboth within and across projects. This necessitates BEF data being preserved following the FAIR principles (Wilkinson et al., 2016): data should be findable, accessible, interoperable, and reusable. This urgent need was described even before the term FAIR was coined (Hampton et al., 2013). For data to be findable, it needs to be described with rich metadata. While suitable annotation schemes exist for some types of biodiversity data (e.g., ABCD for collection data or Darwin Core for occurrence data), they are still lacking for more complex BEF data. The Easy Annotation Scheme for Ecology (Pfaff et al., 2017) or BioSchemas (http://bioschemas.org; Gray et al., 2017), for instance, aim to alleviate this problem. In addition to better annotation schemes, better tools to reduce the human effort in creating these annotations are needed. First examples for such approaches in other disciplines show the general feasibility (Rodrigo et al., 2018).

The best described dataset will not be found, if no appropriate search engines exist. Even though Google recently launched a dataset search, in general, this topic is not yet well researched and poses a number of fundamental challenges (Chapman et al., 2019). Besides finding relevant data, integrating this data is a challenging and labor-intense task. Both tasks could be made considerably easier by the usage of semantic web technologies, in 
particular the usage of ontologies (Gruber, 1993) and compliance to the linked open data principles (Bizer et al., 2008). This is also addressed in the parts of the FAIR principles related to interoperability and reusability. Finally, there is growing awareness, that preserving data alone is not sufficient for reproducibility. Rather, analysis tools and workflows need to be preserved as well (Hardisty et al., 2019). Culturally, a shift is needed to incentivize proper data management and sharing. Although there are warnings stating that a raise in openly available datasets might create the illusion of "a free lunch for all" and that this system will collapse, if the considerable effort that goes into providing datasets is not properly incentivized (Escribano et al., 2018), we believe that open data are absolutely necessary to facilitate fast scientific progress.

\subsection{Operationalizing BEF insights for ecosystem management, society, and decision making}

"A mix of governance options, policies and management practices is available for public and private actors in Europe and Central Asia, but further commitment is needed to adopt and effectively implement them to address the drivers of change, to safeguard biodiversity and to ensure nature's contributions to people for a good quality of life."

IPBES (2018)

With the rising human population size, per capita consumption, and subsequent ecosystem service demands, there is an increasing need for bringing the ecological, fundamental BEF knowledge into action in order to develop applications for the sustainable management of ecosystems, such as agroecosystems (Isbell et al., 2017a,b). Will ecosystems be managed in an ecologically sustainable way or will increasing demands be temporarily compensated by higher management intensity only to be followed by long-term depletion of agriculturally used soils? Indeed, recent studies have pinpointed many potential benefits of increased biodiversity in agroecosystems and production forests (Isbell et al., 2017b; Gérard et al., 2017; Martin-Guay et al., 2018; Pretty, 2018). These conclusions are supported by a long history of intercropping literature that highlights the importance of increasing biodiversity in space and time to maintain crop yields (e.g., Darwin, 1859; Trenbath, 1974; Vandermeer, 1990). In this context, BEF research has the potential to apply the multifunctionality concept (Byrnes et al., 2014; Hector and Bagchi, 2007) to move beyond considering multifunctionality a suite of independent functions, but rather to consider synergies and trade-offs among different ecosystem services 
(Fig. 3; Allan et al., 2015; Binder et al., 2018; Giling et al., 2019; Hines et al., 2015b; Manning et al., 2018; Meyer et al., 2018; see also Manning et al., 2019 for an in-depth discussion of this topic). Biodiversity potentially provides a partial substitute for many costly and non-sustainable agricultural management practices, such as the application of fertilizers, pesticides, imported pollinators, and irrigation (Finger and Buchmann, 2015; Isbell et al., 2017b; Tilman et al., 2006; Weigelt et al., 2009).

There is increasing concern that the ongoing loss of biodiversity may affect and diminish the provision of ecosystem services in the future (Cardinale et al., 2012; IPBES, 2018; Manning et al., 2018; Ricketts et al., 2016; Wall et al., 2015). While some key ecological processes may be well understood, such patterns can be difficult to translate into quantitative relationships suitable for use in an ecosystem service context. There is a need to derive quantitative "pressure-response functions" linking anthropogenic pressures with ecosystem functions that underpin key climate, waterquality, and food-regulating services. This requires the joint analysis of the complex, sometimes conflicting or interactive, effects of multiple anthropogenic pressures on different ecosystem functions and the role of biodiversity as a mediating factor determining how anthropogenic pressures translate into changes in ecosystem services. Challenges relate to the differing spatial scales and configuration of anthropogenic pressures and ecosystem service beneficiaries, and uncertainties associated with the time lags between anthropogenic pressures and ecosystem responses (Isbell et al., 2015b). Accordingly, future research needs to employ a quantitative, multi-parameter approach to assess the nature of linkages between biodiversity, ecosystem processes, and ecosystem services (Giling et al., 2019; Manning et al., 2018) within and across ecosystem boundaries (Barnes et al., 2018). This involves the effects of anthropogenic pressures on these linkages, including reversal of pressures through conservation and restoration management, and likely threshold or hysteresis functions (Isbell et al., 2013).

Results from the last decade of BEF research tend to suggest that we need to conserve a large proportion of existing species, rather than few selected species, to maximize ecosystem service provisioning across spatial and temporal scales (Isbell et al., 2011; Meyer et al., 2018; Reich et al., 2012; Winfree et al., 2018; but see Kleijn et al., 2015). BEF research has to accept the challenge to embrace socio-ecological systems with their different drivers and interaction networks (e.g., including humans; Bohan et al., 2016; Dee et al., 2017). This means, for instance, building BEF experiments based on communities realized under (more) realistic land-use regimes 
regarding current and future stakeholder priorities. Here, e.g., disturbances, restoration projects, and changes in management due to different financial incentives may offer real-world replicated experiments. Scientists will have to more deliberately collaborate with national or federal agencies to develop strategies to become engaged in such projects early enough.

Fully embracing socio-ecological processes can only happen at larger scales and adds several layers of complexity to research projects (Thompson et al., 2018). For operationalizing this goal, food web network theory can meet social network theory to develop combined assessments (Dee et al., 2017). It will be important to identify vulnerabilities in the network(s) and critical bottlenecks to perform opportunity and risk assessments. Knowledge about risk factors can then inform where and when to best employ management interventions. Ultimately, BEF outcomes have to be translated to show policymakers and the general public the value of biodiversity, including consequences of biodiversity decline for human well-being and health, as well as economic aspects, such as jobs, revenues, and the global climate and economy. Moreover, to date, few biodiversity studies have expressed the impact of biodiversity loss on the global warming potential (Isbell et al., 2015b) — a metric accessible to policy makers and commonly used in the IPCC reports to compare whether the greenhouse gas balance of ecosystems has a net warming or cooling effect on climate (IPCC, 2014). Thus, studies linking biodiversity change with global warming potential would not only be of great fundamental value, but could also lead to insights that are of great value for the society at large, and that could be disseminated through e.g. IPBES discussions and reports.

\section{Concluding remarks}

The BEF research field faces the critical challenge to simultaneously develop a more mechanistic understanding of BEF relationships and their context-dependencies as well as to scale up from the plot-level mechanisms and processes to management-relevant spatial and temporal scales in order to operationalize BEF insights for ecosystem management, society, and decision making. Here, we argue that further exploring trophic (e.g., Barnes et al., 2018) and non-trophic interactions (e.g., competition, facilitation; Ferlian et al., 2018) in multitrophic communities will be key to investigate the consequences of non-random biodiversity change as well as the ecoevolutionary underpinnings and implications of BEF relationships. As a consequence, the study of biotic interactions needs to consider the interaction 
history of the involved organisms (Zuppinger-Dingley et al., 2014). Evolutionary history may integrate information about past trophic and non-trophic interactions and thus determine the functioning of species in complex communities. As such, this knowledge may not only be essential to mechanistically understand BEF relationships, but also to develop applications for sustainable agroecosystems (Isbell et al., 2017a; Wang et al., 2019), advance ecological restoration to maintain ecosystem functioning (Kettenring et al., 2014), and sustain the integrity of Earth's ecosystems.

\section{Acknowledgements}

The Jena Experiment is funded by the Deutsche Forschungsgemeinschaft (DFG, German Research Foundation; FOR 1451), with additional support by the Friedrich Schiller University Jena, the Max Planck Institute for Biogeochemistry, and the Swiss National Science Foundation (SNF). This project received additional support from the European Research Council (ERC) under the European Union's Horizon 2020 research and innovation program (grant agreement no. 677232 to NE) and the German Centre for Integrative Biodiversity Research Halle-Jena-Leipzig, funded by the German Research Foundation (FZT 118). MJ was additionally supported by the Swiss National Science Foundation. HB, FB, BS, MSL and CW acknowledge the funding for the BEF-China experiment by the German Research Foundation (DFG FOR 891) and the Swiss National Science Foundation (SNSF nos. 130720 and 147092). FI acknowledges funding support from the US National Science Foundation's Long-Term Ecological Research program (LTER) (DEB-1234162), as well as the LTER Network Communications Office (DEB1545288). HB, SH, MSL, FvdP and CW acknowledge funding support from the European Union Seventh Framework Programme (FP7/2007-2013) under grant agreement no 265171, project FunDivEUROPE. We acknowledge comments by Tiffany Knight, Jonathan Levine, Yvonne Oelmann, Henrique Pereira, Wolfgang Wilcke, and Elizabeth Wolkovich during the "15 Years of the Jena Experiment" workshop or on earlier versions of this manuscript. Figs 1, 2, 3, and 5 were prepared by Thomas Fester (Scivit).

\section{References}

Adler, P.B., Seabloom, E.W., Borer, E.T., Hillebrand, H., Hautier, Y., Hector, A., Harpole, W.S., Halloran, L.R.O., Grace, J.B., Anderson, T.M., Bakker, J.D., Biederman, L., et al., 2011. Productivity is a poor predictor of plant species richness. Science 1750, 1750-1754.

Allan, E., Weisser, W., Weigelt, A., Roscher, C., Fischer, M., Hillebrand, H., 2011. More diverse plant communities have higher functioning over time due to turnover in complementary dominant species. Proc. Natl. Acad. Sci. U. S. A. 108, 17034-17039.

Allan, E., Weisser, W.W., Fischer, M., Schulze, E.D., Weigelt, A., Roscher, C., Baade, J., Barnard, R.L., Beßler, H., Buchmann, N., Ebeling, A., Eisenhauer, N., et al., 2013. A comparison of the strength of biodiversity effects across multiple functions. Oecologia 173, 223-237.

Allan, E., Manning, P., Alt, F., Binkenstein, J., Blaser, S., Blüthgen, N., Böhm, S., Grassein, F., Hölzel, N., Klaus, V.H., Kleinebecker, T., Morris, E.K., et al., 2015. Land use intensification alters ecosystem multifunctionality via loss of biodiversity and changes to functional composition. Ecol. Lett. 18, 834-843. 
Baert, J.M., Eisenhauer, N., Janssen, C.R., De Laender, F., 2018. Biodiversity effects on ecosystem functioning respond unimodally to environmental stress. Ecol. Lett. 21, 1191-1199.

Balvanera, P., Pfisterer, A.B., Buchmann, N., He, J.-S., Nakashizuka, T., Raffaelli, D., Schmid, B., 2006. Quantifying the evidence for biodiversity effects on ecosystem functioning and services. Ecol. Lett. 9, 1146-1156.

Balvanera, P., Siddique, I., Dee, L., Paquette, A., Isbell, F., Gonzalez, A., Byrnes, J., O’Connor, M.I., Hungate, B.A., Griffin, J.N., 2014. Linking biodiversity and ecosystem services: current uncertainties and the necessary next steps. Bioscience 64, 49-57.

Bandowe, B.A.M., Leimer, S., Meusel, H., Velescu, A., Dassen, S., Eisenhauer, N., Hoffmann, T., Oelmann, Y., Wilcke, W., 2019. Plant diversity enhances the natural attenuation of polycyclic aromatic compounds (PAHs and oxygenated PAHs) in grassland soils. Soil Biol. Biochem. 129, 60-70.

Bannar-Martin, K.H., Kremer, C.T., Ernest, S.K.M., Leibold, M.A., Auge, H., Chase, J., Declerck, S.A.J., Eisenhauer, N., Harpole, S., Hillebrand, H., Isbell, F., Koffel, T., et al., 2018. Integrating community assembly and biodiversity to better understand ecosystem function: the Community Assembly and the Functioning of Ecosystems (CAFE) approach. Ecol. Lett. 21, 167-180.

Bardgett, R.D., Wardle, D.A., 2010. Aboveground-Belowground Linkages: Biotic Interactions, Ecosystem Processes, and Global Change. Oxford University Press, Oxford.

Barnes, A.D., Jochum, M., Mumme, S., Haneda, N.F., Farajallah, A., Widarto, T.H., Brose, U., 2014. Consequences of tropical land use for multitrophic biodiversity and ecosystem functioning. Nat. Commun. 5, 1-7.

Barnes, A.D., Weigelt, P., Jochum, M., Ott, D., Hodapp, D., Haneda, N.F., Brose, U., 2016. Species richness and biomass explain spatial turnover in ecosystem functioning across tropical and temperate ecosystems. Philos. Trans. R. Soc. B 371 (1694) 20150279.

Barnes, A.D., Jochum, M., Lefcheck, J.S., Eisenhauer, N., Scherber, C., O’Connor, M.I., de Ruiter, P., Brose, U., 2018. Energy flux: the link between multitrophic biodiversity and ecosystem functioning. Trends Ecol. Evol. 33, 186-197.

Barry, K.E., Mommer, L., van Ruijven, J., Wirth, C., Wright, A.J., Bai, Y., Connolly, J., De Deyn, G.B., de Kroon, H., Isbell, F., Milcu, A., Roscher, C., et al., 2019a. The future of complementarity: disentangling causes from consequences. Trends Ecol. Evol. 34, 167-180.

Barry, K.E., de Kroon, H., Dietrich, P., Harpole, W.S., Roeder, A., Schmid, B., Clark, A.T., Mayfield, M.M., et al., 2019b. Linking local species coexistence to ecosystem functioning: a conceptual framework from ecological first principles in grassland ecosystems. Adv. Ecol. Res. 61, 265-296.

Barry, K.E., Weigelt, A., van Ruijven, J., de Kroon, H., Ebeling, A., Eisenhauer, N., Gessler, A., Ravenek, J.M., et al., 2019c. Above- and belowground overyielding are related at the community and species level in a grassland biodiversity experiment. Adv. Ecol. Res. 61, 55-89.

Berendse, F., van Ruijven, J., Jongejans, E., Keesstra, S., 2015. Loss of plant species diversity reduces soil erosion resistance. Ecosystems 18, 881-888.

Beugnon, R., Steinauer, K., Barnes, A.D., Ebeling, A., Roscher, C., Eisenhauer, N., 2019. Plant functional trait identity and diversity effects on soil meso- and macrofauna in an experimental grassland. Adv. Ecol. Res. 61, 163-184.

Binder, S., Isbell, F., Polasky, S., Catford, J.A., Tilman, D., 2018. Grassland biodiversity can pay. Proc. Natl. Acad. Sci. U. S. A. 115, 3876-3881.

Bizer, C., Heath, T., Berners-Lee, T., 2008. Linked data: principles and state of the art. In: Proceedings of the 17th International Conference on World Wide WebWWW'08, pp. 1265-1266. 
Bohan, D., Landuyt, D., Ma, A., Macfadyen, S., Martinet, V., Massol, F., et al., 2016. Networking our way to better ecosystem service provision. Trends Ecol. Evol. 31, 105-115.

Borer, E.T., Harpole, W.S., Adler, P.B., Lind, E.M., Orrock, J.L., Seabloom, E.W., Smith, M.D., 2014. Finding generality in ecology: a model for globally distributed experiments. Methods Ecol. Evol. 5, 65-73.

Borer, E.T., Grace, J.B., Harpole, W.S., MacDougall, A.S., Seabloom, E.W., 2017. A decade of insights into grassland ecosystem responses to global environmental change. Nat. Ecol. Evol. 1, 0118.

Bosse, M., Spurgin, L.G., Laine, V.N., Cole, E.F., Firth, J.A., Gienapp, P., Gosler, A.G., Mcmahon, K., Poissant, J., Verhagen, I., Groenen, M.A.M., Van Oers, K., et al., 2017. Recent natural selection causes adaptive evolution of an avian polygenic trait. Science 358, 365-368.

Bowler, D., Bjorkmann, A., Dornelas, M., Myers-Smith, I., Navarro, L., Niamir, A., Supp, S., Waldock, C., Vellend, M., Blowes, S., Boehning-Gaese, K., Bruelheide, H., et al., 2018. The geography of the anthropocene differs between the land and the sea. BioRxiv. https://doi.org/10.1101/432880.

Bracken, M.E.S., Friberg, S.E., Gonzalez-Dorantes, C.A., Williams, S.L., 2008. Functional consequences of realistic biodiversity changes in a marine ecosystem. Proc. Natl. Acad. Sci. U. S. A. 105, 924-928.

Brose, U., Hillebrand, H., 2016. Biodiversity and ecosystem functioning in soil. Philos. Trans. R. Soc. B 371, 20150267.

Brose, U., Ostling, A., Harrison, K., Martinez, N.D., 2004. Unified spatial scaling of species and their trophic interactions. Nature 428, 167-171.

Brose, U., Blanchard, J.L., Eklöf, A., Galiana, N., Hartvig, M., Hirt, M.R., Kalinkat, G., Nordström, M.C., O’Gorman, E.J., Rall, B.C., Schneider, F.D., Thébault, E., Jacob, U., 2017. Predicting the consequences of species loss using size-structured biodiversity approaches. Biol. Rev. 92, 684-697.

Bruelheide, H., Nadrowski, K., Assmann, T., Bauhus, J., Both, S., Buscot, F., Chen, X.Y., Ding, B., Durka, W., Erfmeier, A., Gutknecht, J.L.M., Guo, D., et al., 2014. Designing forest biodiversity experiments: general considerations illustrated by a new large experiment in subtropical China. Methods Ecol. Evol. 5, 74-89.

Bruno, J.F., Lee, S.C., Kertesz, J.S., Carpenter, R.C., Long, Z.T., Duffy, J.E., 2006. Partitioning the effects of algal species identity and richness on benthic marine primary production. Oikos 115, 170-178.

Bruno, J.F., Boyer, K.E., Duffy, E., Lee, S.C., 2008. Relative and interactive effects of plant and grazer richness in a benthic marine community. Ecology 89, 2518-2528.

Brust, C.A., Burghardt, T., Groenenberg, M., Käding, C., Kühl, H.S., Manguette, M.L., Denzler, J., 2018. Towards automated visual monitoring of individual gorillas in the wild. In: Proceedings-2017 IEEE International Conference on Computer Vision Workshops, ICCVW 2017, pp. 2820-2830.

Byrnes, J.E.K., Gamfeldt, L., Isbell, F., Lefcheck, J.S., Griffin, J.N., Hector, A., Cardinale, B.J., Hooper, D.U., Dee, L.E., Duffy, J.E., 2014. Investigating the relationship between biodiversity and ecosystem multifunctionality: challenges and solutions. Methods Ecol. Evol. 5, 111-124.

Cabello, J., Fernández, N., Alcaraz-Segura, D., Oyonarte, C., Pineiro, G., Altesor, A., Delibes, M., Paruelo, J.M., 2012. The ecosystem functioning dimension in conservation: insights from remote sensing. Biodivers. Conserv. 21, 3287-3305.

Cadotte, M.W., 2013. Experimental evidence that evolutionarily diverse assemblages result in higher productivity. Proc. Natl. Acad. Sci. U. S. A. 110, 8996-9000.

Cadotte, M.W., Cardinale, B.J., Oakley, T.H., 2008. Evolutionary history and the effect of biodiversity on plant productivity. Proc. Natl. Acad. Sci. U. S. A. 105, 17012-17017. 
Cardillo, M., Mace, G.M., Jones, K.E., Bielby, J., Bininda-Emonds, O.R.P., Sechrest, W., Orme, C.D.L., Purvis, A., 2005. Multiple causes of high extinction risk in large mammal species. Science 309, 1239-1241.

Cardinale, B.J., 2011. Biodiversity improves water quality through niche partitioning. Nature 472, 86-91.

Cardinale, B.J., Palmer, M.A., Collins, S.L., 2002. Species diversity enhances ecosystem functioning through interspecific facilitation. Nature 415, 426-429.

Cardinale, B.J., Harvey, C.T., Gross, K., Ives, A.R., 2003. Biodiversity and biocontrol: emergent impacts of a multi-enemy assemblage on pest suppression and crop yield in an agroecosystem. Ecol. Lett. 6, 857-865.

Cardinale, B.J., Wright, J.P., Cadotte, M.W., Carroll, I.T., Hector, A., Srivastava, D.S., Loreau, M., Weis, J.J., 2007. Impacts of plant diversity on biomass production increase through time because of species complementarity. Proc. Natl. Acad. Sci. U. S. A. 104, 18123-18128.

Cardinale, B.J., Matulich, K.L., Hooper, D.U., Byrnes, J.E., Duffy, E., Gamfeldt, L., Balvanera, P., O'Connor, M.I., Gonzalez, A., 2011. The functional role of producer diversity in ecosystems. Am. J. Bot. 98, 572-592.

Cardinale, B.J., Duffy, J.E., Gonzalez, A., Hooper, D.U., Perrings, C., Venail, P., Narwani, A., Mace, G.M., Tilman, D., Wardle, D.A., et al., 2012. Biodiversity loss and its impact on humanity. Nature 486, 59-67.

Carroll, S.P., Hendry, A.P., Reznick, D.N., Fox, C.W., 2007. Evolution on ecological timescales. Funct. Ecol. 21, 387-393.

Chapin III, F.S., Zavaleta, E.S., Eviner, V.T., Naylor, R.L., Vitousek, P.M., Reynolds, H.L., Hooper, D.U., Lavorel, S., Sala, O.E., Hobbie, S.E., et al., 2000. Consequences of changing biodiversity. Nature 405, 234-242.

Chapman, A., Simperl, E., Koesten, L., Konstantinidis, G., Ibáñez-Gonzalez, L.-D., Kacprzak, E., Groth, P., 2019. Dataset search: a survey. arXiv. 1901.00735.

Charmantier, A., Mccleery, R.H., Cole, L.R., Perrins, C., Kruuk, L.E.B., Sheldon, B.C., 2008. Adaptive phenotypic plasticity in response to climate change in a wild bird population. Science 800, 800-804.

Chase, J.M., Leibold, M.A., 2003. Ecological Niches: Linking Classical and Contemporary Approaches. University of Chicago Press, Chicago.

Chesson, P., Pacala, S., Neuhauser, C., 2001. Environmental niches and ecosystem functioning. In: Kinzig, A.P., Pacala, S., Tilman, D. (Eds.), The Functional Consequences of Biodiversity. Princeton University Press, pp. 213-245.

Civitello, D.J., Cohen, J., Fatima, H., Halstead, N.T., Liriano, J., McMahon, T.A., Ortega, C.N., Sauer, E.L., Sehgal, T., Young, S., Rohr, J.R., 2015. Biodiversity inhibits parasites: broad evidence for the dilution effect. Proc. Natl. Acad. Sci. U. S. A. 112, 8667-8671.

Clark, C.M., Cleland, E.E., Collins, S.L., Fargione, J.E., Gough, L., Gross, K.L., Pennings, S.C., Suding, K.N., Grace, J.B., 2007. Environmental and plant community determinants of species loss following nitrogen enrichment. Ecol. Lett. 10, 596-607.

Connolly, J., Bell, T., Bolger, T., Brophy, C., Carnus, T., Finn, J.A., Kirwan, L., Isbell, F., Levine, J., Lüscher, A., Picasso, V., Roscher, C., et al., 2013. An improved model to predict the effects of changing biodiversity levels on ecosystem function. J. Ecol. 101, 344-355.

Costanza, R., D’Arge, R., de Groot, R., Farber, S., Grasso, M., Hannon, B., Limburg, K., Naeem, S., O’Neill, R.V., Paruelo, J., Raskin, R.G., Sutton, P., van den Belt, M., 1997. The value of the world's ecosystem services and natural capital. Nature 387, 253-260.

Coulis, M., Fromin, N., David, J.F., Gavinet, J., Clet, A., Devidal, S., Roy, J., Hättenschwiler, S., 2015. Functional dissimilarity across trophic levels as a driver of soil processes in a Mediterranean decomposer system exposed to two moisture levels. Oikos 124, 1304-1316. 
Cowles, J.M., Wragg, P.D., Wright, A.J., Powers, J.S., Tilman, D., 2016. Shifting grassland plant community structure drives positive interactive effects of warming and diversity on aboveground net primary productivity. Glob. Chang. Biol. 22, 741-749.

Craven, D., Isbell, F., Manning, P., Connolly, J., Bruelheide, H., Ebeling, A., Roscher, C., van Ruijven, J., Weigelt, A., Wilsey, B., Beierkuhnlein, C., de Luca, E., et al., 2016. Plant diversity effects on grassland productivity are robust to both nutrient enrichment and drought. Philos. Trans. R. Soc. B 371, 20150277.

Craven, D., Eisenhauer, N., et al., 2018. Multiple facets of biodiversity drive the diversity-stability relationship. Nat. Ecol. Evol. 2, 1579-1587.

Craven, D., Winter, M., Hotzel, K., Gaikwad, J., Eisenhauer, N., Hohmuth, M., KönigRies, B., Wirth, C., 2019. Evolution of interdisciplinarity in biodiversity science. Ecol. Evol. 9, 6744-6755.

Crutsinger, G.M., Collins, M.D., Fordyce, J.A., Gompert, Z., Nice, C.C., Sanders, N.J., 2006. Plant genotypic diversity predicts community structure and governs an ecosystem process. Science 313, 966-968.

Dallimer, M., Irvine, K.N., Skinner, A.M.J., Davies, Z.G., Rouquette, J.R., Maltby, L.L., Warren, P.H., Armsworth, P.R., Gaston, K.J., 2012. Biodiversity and the feel-good factor: understanding associations between self-reported human well-being and species richness. Bioscience 62, 47-55.

Darwin, C., 1859. On the Origins of Species by Means of Natural Selection. John Murray, United Kingdom.

Darwin, C., Wallace, A., 1858. On the tendency of species to form varieties; and on the perpetuation of varieties and species by natural means of selection. J. Proc. Linn. Soc. Lond. 3, 45-62.

De Laender, F., Rohr, J.R., Ashauer, R., Baird, D.J., Berger, U., Eisenhauer, N., Grimm, V., Hommen, U., Maltby, L., Pomati, F., Roessink, I., Radchuk, V., Van den Brink, P.J., 2016. Re-introducing environmental change drivers in biodiversityecosystem functioning research. Trends Ecol. Evol. 31, 905-915.

de Mazancourt, C., Isbell, F., Larocque, A., Berendse, F., De Luca, E., Grace, J.B., Haegeman, B., Polley, W.H., Roscher, C., Schmid, B., Tilman, D., van Ruijven, J., et al., 2013. Predicting ecosystem stability from community composition and biodiversity. Ecol. Lett. 16, 617-625.

Dee, L.E., Allesina, S., Bonn, A., Eklöf, A., Gaines, S.D., Hines, J., Jacob, U., McDonaldMadden, E., Possingham, H., Schröter, M., Thompson, R.M., 2017. Operationalizing network theory for ecosystem service assessments. Trends Ecol. Evol. 32, 118-130.

Dell, A.I., Bender, J.A., Branson, K., Couzin, I.D., de Polavieja, G.G., Noldus, L.P., Pérez-Escudero, A., Perona, P., Straw, A.D., Wikelski, M., Brose, U., 2014. Automated image-based tracking and its application in ecology. Trends Ecol. Evol. $29,417-428$.

Dias, A.T.C., Berg, M.P., de Bello, F., Van Oosten, A.R., Bílá, K., Moretti, M., 2013. An experimental framework to identify community functional components driving ecosystem processes and services delivery. J. Ecol. 101, 29-37.

Díaz, S., Symstad, A.J., Chapin, F.S., Wardle, D.A., Huenneke, L.F., 2003. Functional diversity revealed by removal experiments. Trends Ecol. Evol. 18, 140-146.

Dirzo, R., Young, H.S., Galetti, M., Ceballos, G., Isaac, N.J.B., Collen, B., 2014. Defaunation in the anthropocene. Science 345, 401-406.

Donohue, I., Hillebrand, H., Montoya, J.M., Petchey, O.L., Pimm, S.L., Fowler, M.S., Healy, K., Jackson, A.L., Lurgi, M., McClean, D., O'Connor, N.E., O'Gorman, E.J., Yang, Q., 2016. Navigating the complexity of ecological stability. Ecol. Lett. 19, 1172-1185. 
Dornelas, M., Gotelli, N.J., McGill, B., Shimadzu, H., Moyes, F., Sievers, C., Magurran, A.E., 2014. Assemblage time series reveal biodiversity change but not systematic loss. Science 344, 296-299.

Dossena, M., Yvon-Durocher, G., Grey, J., Montoya, J.M., Perkins, D.M., Trimmer, M., Woodward, G., 2012. Warming alters community size structure and ecosystem functioning. Proc. R. Soc. B Biol. Sci. 279, 3011-3019.

Duffy, J.E., 2002. Biodiversity and ecosystem function: the consumer connection. Oikos 99, 201-219.

Duffy, J.E., Cardinale, B.J., France, K.E., McIntyre, P.B., Thébault, E., Loreau, M., 2007. The functional role of biodiversity in ecosystems: Incorporating trophic complexity. Ecol. Lett. 10, 522-538.

Duffy, E.J., Godwin, C.M., Cardinale, B.J., 2017. Biodiversity effects in the wild are common and as strong as key drivers of productivity. Nature 549, 261-264.

Ebeling, A., Klein, A.-M., Schumacher, J., Weisser, W.W., Tscharntke, T., 2008. How does plant richness affect pollinator richness and temporal stability of flower visits? Oikos 117, 1808-1815.

Ebeling, A., Pompe, S., Baade, J., Eisenhauer, N., Hillebrand, H., Proulx, R., Roscher, C., Schmid, B., Wirth, C., Weisser, W.W., 2014. A trait-based experimental approach to understand the mechanisms underlying biodiversity-ecosystem functioning relationships. Basic Appl. Ecol. 15, 229-240.

Ebeling, A., Rzanny, M., Lange, M., Eisenhauer, N., Hertzog, L.R., Meyer, S.T., Weisser, W.W., 2018. Plant diversity induces shifts in the functional structure and diversity across trophic levels. Oikos 127, 208-219.

Eisenhauer, N., 2017. Consumers control carbon. Nat. Ecol. Evol. 1, 1596-1597.

Eisenhauer, N., Türke, M., 2018. From climate chambers to biodiversity chambers. Front. Ecol. Environ. 16, 136-137.

Eisenhauer, N., Beßler, H., Engels, C., Gleixner, G., Habekost, M., Milcu, A., Partsch, S., Sabais, A.C.W., Scherber, C., Steinbeiss, S., Weigelt, A., Weisser, W.W., Scheu, S., 2010. Plant diversity effects on soil microorganisms support the singular hypothesis. Ecology 91, 485-496.

Eisenhauer, N., Milcu, A., Allan, E., Nitschke, N., Scherber, C., Temperton, V., Weigelt, A., Weisser, W.W., Scheu, S., 2011. Impact of above- and below-ground invertebrates on temporal and spatial stability of grassland of different diversity. J. Ecol. 99, 572-582.

Eisenhauer, N., Reich, P.B., Scheu, S., 2012. Increasing plant diversity effects on productivity with time due to delayed soil biota effects on plants. Basic Appl. Ecol. 13, 571-578.

Eisenhauer, N., Dobies, T., Cesarz, S., Hobbie, S.E., Meyer, R.J., Worm, K., Reich, P.B., 2013. Plant diversity effects on soil food webs are stronger than those of elevated $\mathrm{CO}_{2}$ and $\mathrm{N}$ deposition in a long-term grassland experiment. Proc. Natl. Acad. Sci. U. S. A. 110, 6889-6894.

Eisenhauer, N., Barnes, A.D., Cesarz, S., Craven, D., Ferlian, O., Gottschall, F., Hines, J., Sendek, A., Siebert, J., Thakur, M.P., Türke, M., 2016. Biodiversity-ecosystem function experiments reveal the mechanisms underlying the consequences of biodiversity change in real world ecosystems. J. Veg. Sci. 27, 1061-1070.

Eisenhauer, N., Hines, J., Isbell, F., van Der Plas, F., Hobbie, S.E., Kazanski, C.E., Lehmann, A., Liu, M., Lochner, A., Rillig, M.C., Vogel, A., Worm, K., Reich, P.B., 2018. Plant diversity maintains multiple soil functions in future environments. eLife 7, e41228.

Eisenhauer, N., Bonn, A., Guerra, A.C., 2019. Recognizing the quiet extinction of invertebrates. Nat. Commun. 10, 50.

Ellegren, H., 2014. Genome sequencing and population genomics in non-model organisms. Trends Ecol. Evol. 29, 51-63. 
Elton, C.S., 1958. The Ecology of Invasions by Animals and Plants. Methuen and Co. Ltd., London.

Escribano, N., Galicia, D., Ariño, A.H., 2018. The tragedy of the biodiversity data commons: a data impediment creeping nigher? Database, 1-6.

Everwand, G., Rösch, V., Tscharntke, T., Scherber, C., 2014. Disentangling direct and indirect effects of experimental grassland management and plant functional-group manipulation on plant and leafhopper diversity. BMC Ecol. 14, 1.

Fahrig, L., 2017. Ecological responses to habitat fragmentation per se. Annu. Rev. Ecol. Evol. Syst. 48, 1-23.

Fahrig, L., Arroyo-Rodríguez, V., Bennett, J.R., Boucher-Lalonde, V., Cazetta, E., Currie, D.J., Eigenbrod, F., Ford, A.T., Harrison, S.P., Jaeger, J.A.G., Koper, N., Martin, A.E., et al., 2019. Is habitat fragmentation bad for biodiversity? Biol. Conserv. 230, 179-186.

Ferlian, O., Cesarz, S., Craven, D., Hines, J., Barry, K.E., Bruelheide, H., Buscot, F., Haider, S., Heklau, H., Herrmann, S., Kühn, P., Pruschitzki, U., et al., 2018. Mycorrhiza in tree diversity-ecosystem function relationships: conceptual framework and experimental implementation. Ecosphere 9, e02226.

Finger, R., Buchmann, N., 2015. An ecological economic assessment of risk-reducing effects of species diversity in managed grasslands. Ecol. Econ. 110, 89-97.

Finn, J.A., Kirwan, L., Connolly, J., Sebastià, M.T., Helgadottir, A., Baadshaug, O.H., Bélanger, G., Black, A., Brophy, C., Collins, R.P., Čop, J., Dalmannsdóttir, S., et al., 2013. Ecosystem function enhanced by combining four functional types of plant species in intensively managed grassland mixtures: A 3-year continental-scale field experiment. J. Appl. Ecol. 50, 365-375.

Fornara, D.A., Tilman, D., 2008. Plant functional composition influences rates of soil carbon and nitrogen accumulation. J. Ecol. 96, 314-322.

Fox, J.W., 2005. Interpreting the "selection effect" of biodiversity on ecosystem function. Ecol. Lett. 8, 846-856.

Fox, J.W., Vasseur, D., Cotroneo, M., Guan, L., Simon, F., 2017. Population extinctions can increase metapopulation persistence. Nat. Ecol. Evol. 1, 1271-1278.

Fridley, J.D., 2002. Resource availability dominates and alters the relationship between species diversity and ecosystem productivity in experimental plant communities. Oecologia 132, 271-277.

Galiana, N., Lurgi, M., Claramunt-Lopez, B., Fortin, M.J., Leroux, S., Cazelles, K., Gravel, D., Montoya, J.M., 2018. The spatial scaling of species interaction networks. Nat. Ecol. Evol. 2, 782-790.

Gérard, A., Wollni, M., Hölscher, D., Irawan, B., Sundawati, L., Teuscher, M., Kreft, H., 2017. Oil-palm yields in diversified plantations: Initial results from a biodiversity enrichment experiment in Sumatra, Indonesia. Agric. Ecosyst. Environ. 240, 253-260.

Gessner, M.O., Swan, C.M., Dang, C.K., McKie, B.G., Bardgett, R.D., Wall, D.H., Hättenschwiler, S., 2010. Diversity meets decomposition. Trends Ecol. Evol. 25, 372-380.

Gilarranz, L.J., Rayfield, B., Liñán-Cembrano, G., Bascompte, J., Gonzalez, A., 2017. Effects of network modularity on the spread of perturbation impact in experimental metapopulations. Science 357, 199-201.

Giling, D.P., Beaumelle, L., Phillips, H.R.P., Cesarz, S., Eisenhauer, N., Ferlian, O., Gottschall, F., Guerra, C., Hines, J., Sendek, A., Siebert, J., Thakur, M.P., Barnes, A.D., 2019. A niche for ecosystem multifunctionality in global change research. Glob. Chang. Biol. 25, 763-774.

Givnish, T.J., 1994. Does diversity beget stability? Nature 371, 113-114.

Gonzalez, A., Thompson, P., Loreau, M., 2017. Spatial ecological networks: planning for sustainability in the long-term. Curr. Opin. Environ. Sustain. 29, 187-197. 
Gossner, M.M., Lewinsohn, T.M., Kahl, T., Grassein, F., Boch, S., Prati, D., Birkhofer, K., Renner, S.C., Sikorski, J., Wubet, T., Arndt, H., Baumgartner, V., et al., 2016. Land-use intensification causes multitrophic homogenization of grassland communities. Nature 540, 266-269.

Götzenberger, L., de Bello, F., Bråthen, K.A., Davison, J., Dubuis, A., Guisan, A., Lepš, J., Lindborg, R., Moora, M., Pärtel, M., Pellissier, L., Pottier, J., et al., 2012. Ecological assembly rules in plant communities-approaches, patterns and prospects. Biol. Rev. 87, 111-127.

Gounand, I., Little, C.J., Harvey, E., Altermatt, F., 2018. Cross-ecosystem carbon flows connecting ecosystems worldwide. Nat. Commun. 9, 4825.

Grace, J.B., Anderson, T.M., Seabloom, E.W., Borer, E.T., Adler, P.B., Harpole, W.S., Hautier, Y., Hillebrand, H., Lind, E.M., Pärtel, M., Bakker, J.D., Buckley, Y.M., et al., 2016. Integrative modelling reveals mechanisms linking productivity and plant species richness. Nature 529, 390-393.

Grass, I., Jauker, B., Steffan-Dewenter, I., Tscharntke, T., Jauker, F., 2018. Past and potential future effects of habitat fragmentation on structure and stability of plant-pollinator and host-parasitoid networks. Nat. Ecol. Evol. 2, 1408-1417.

Gravel, D., Massol, F., Canard, E., Mouillot, D., Mouquet, N., 2011. Trophic theory of island biogeography. Ecol. Lett. 14, 1010-1016.

Gray, A.J.G., Goble, C., Jimenez, R.C., 2017. Bioschemas: From Potato Salad to Protein Annotation. CEUR Workshop Proceedings.

Griffin, J.N., Jenkins, S.R., Gamfeldt, L., Jones, D., Hawkins, S.J., Thompson, R.C., 2009. Spatial heterogeneity increases the importance of species richness for an ecosystem process. Oikos 118, 1335-1342.

Grime, J.P., 1997. Biodiversity and ecosystem function: the debate deepens. Science 277, 1260-1261.

Grime, J.P., 1998. Benefits of plant diversity to ecosystems: immediate, filter and founder effects. J. Ecol. 86, 902-910.

Grossman, J.J., Vanhellemont, M., Barsoum, N., Bauhus, J., Bruelheide, H., Castagneyrol, B., Cavender-Bares, J., Eisenhauer, N., Ferlian, O., Gravel, D., Hector, A., Jactel, H., et al., 2018. Synthesis and future research directions linking tree diversity to growth, survival, and damage in a global network of tree diversity experiments. Environ. Exp. Bot. 152, 68-89.

Gruber, T.R., 1993. A translation approach to portable ontologies. Knowl. Acquis. 5, 199-220.

Guerrero-Ramírez, N.R., Eisenhauer, N., 2017. Trophic and non-trophic interactions influence the mechanisms underlying biodiversity-ecosystem functioning relationships under different abiotic conditions. Oikos 126, 1748-1759.

Guerrero-Ramírez, N.R., Craven, D., Reich, P.B., Ewel, J.J., Koricheva, J., Parrotta, J.A., Auge, H., Erickson, H.E., Forrester, D.I., Hector, A., Joshi, J., Montagnini, F., 2017. Diversity-dependent temporal divergence of ecosystem functioning in experimental ecosystems. Nat. Ecol. Evol. 1, 1639-1642.

Haddad, N.M., Holyoak, M., Mata, T.M., Davies, K.F., Melbourne, B.A., Preston, K., 2008. Species traits predict the effects of disturbance and productivity on diversity. Ecol. Lett. 11, 348-356.

Haddad, N.M., Crutsinger, G.M., Gross, K., Haarstad, J., Knops, J.M.H., Tilman, D., 2009. Plant species loss decreases arthropod diversity and shifts trophic structure. Ecol. Lett. 12, 1029-1039.

Hampton, S.E., Strasser, C.A., Tewksbury, J.J., Gram, W.K., Budden, A.E., Batcheller, A.L., Duke, C.S., Porter, J.H., 2013. Big data and the future of ecology. Front. Ecol. Environ. 11, 156-162.

Handa, I.T., Aerts, R., Berendse, F., Berg, M.P., Bruder, A., Butenschoen, O., Chauvet, E., Gessner, M.O., Jabiol, J., Makkonen, M., McKie, B.G., Malmqvist, B., et al., 2014. Consequences of biodiversity loss for litter decomposition across biomes. Nature 509, 218-221. 
Hantsch, L., Braun, U., Scherer-Lorenzen, M., Bruelheide, H., 2013. Tree diversity effects on species richness and infestation of foliar fungal pathogens in European tree diveristy experiments. Ecosphere 4, 81.

Hantsch, L., Bien, S., Radatz, S., Braun, U., Auge, H., Bruelheide, H., 2014. Tree diversity and the role of non-host neighbour tree species in reducing fungal pathogen infestation. J. Ecol. 102, 1673-1687.

Hardisty, A., Roberts, D., 2013. A decadal view of biodiversity informatics: challenges and priorities. BMC Ecol. 13, 16.

Hardisty, A., Michener, W.K., Agosti, D., Garcia, E.A., Bastin, L., Belbin, L., Bowser, A., Buttigieg, P.L., Canhos, D.A.L., Egloff, W., De Giovanni, R., Figueira, R., 2019. The Bari Manifesto: an interoperability framework for essential biodiversity variables. Eco. Inform. 49, 22-31.

Harmon, L.J., Matthews, B., Des Roches, S., Chase, J.M., Shurin, J.B., Schluter, D., 2009. Evolutionary diversification in stickleback affects ecosystem functioning. Nature 458, 1167-1170.

Harpole, W.S., Tilman, D., 2007. Grassland species loss resulting from reduced niche dimension. Nature 446, 791-793.

Harpole, W.S., Sullivan, L.L., Lind, E.M., Firn, J., Adler, P.B., Borer, E.T., Chase, J., Fay, P.A., Hautier, Y., Hillebrand, H., MacDougall, A.S., Seabloom, E.W., et al., 2016. Addition of multiple limiting resources reduces grassland diversity. Nature 537, 93-96.

Hautier, Y., Niklaus, P.A., Hector, A., 2009. Competition for light causes plant biodiversity loss after eutrophication. Science 324, 636-638.

Hautier, Y., Isbell, F., Borer, E.T., Seabloom, E.W., Harpole, W.S., Lind, E.M., MacDougall, A.S., Stevens, C.J., Adler, P.B., Alberti, J., Bakker, J.D., Brudvig, L.A., et al., 2018. Local loss and spatial homogenization of plant diversity reduce ecosystem multifunctionality. Nat. Ecol. Evol. 2, 50-56.

Hector, A., Bagchi, R., 2007. Biodiversity and ecosystem multifunctionality. Nature 448, 188-190.

Hector, A., Hooper, R., 2002. Darwin and the first ecological experiment. Science 295, 639-640.

Hector, A., Schmid, B., Beierkuhnlein, C., Caldeira, M.C., Diemer, M., Dimitrakopoulos, P.G., Finn, J.A., Freitas, H., Giller, P.S., Good, J., Harris, R., Högberg, P., et al., 1999. Plant diversity and productivity experiments in European grasslands. Science 286, 1123-1127.

Hendriks, M., Mommer, L., de Caluwe, H., Smit-Tiekstra, A.E., van der Putten, W.H., de Kroon, H., 2013. Independent variations of plant and soil mixtures reveal soil feedback effects on plant community overyielding. J. Ecol. 101, 287-297.

Hendry, A.P., 2016. Eco-Evolutionary Dynamics. Princeton University Press, Princeton.

Hertzog, L.R., Ebeling, A., Weisser, W.W., Meyer, S.T., 2017. Plant diversity increases predation by ground-dwelling invertebrate predators. Ecosphere 8 e01990.

Hillebrand, H., Matthiessen, B., 2009. Biodiversity in a complex world: consolidation and progress in functional biodiversity research. Ecol. Lett. 12, 1405-1419.

Hillebrand, H., Blasius, B., Borer, E.T., Chase, J.M., Downing, J.A., Eriksson, B.K., Filstrup, C.T., Harpole, W.S., Hodapp, D., Larsen, S., Lewandowska, A.M., Seabloom, E.W., et al., 2018. Biodiversity change is uncoupled from species richness trends: consequences for conservation and monitoring. J. Appl. Ecol. $55,169-184$.

Hines, J., Eisenhauer, N., Drake, B.G., 2015a. Inter-annual changes in detritus-based food chains can enhance plant growth response to elevated atmospheric $\mathrm{CO}_{2}$. Glob. Chang. Biol. 21, 4642-4650. 
Hines, J., van der Putten, W.H., De Deyn, G.B., Wagg, C., Voigt, W., Mulder, C., Weisser, W.W., Engel, J., Melian, C., Scheu, S., Birkhofer, K., Ebeling, A., et al., 2015b. Towards an integration of biodiversity-ecosystem functioning and food web theory to evaluate relationships between multiple ecosystem services. Adv. Ecol. Res. 53, 161-199.

Hines, J., Ebeling, A., Barnes, A.D., Brose, U., Scherber, C., Scheu, S., Tscharntke, T., Weisser, W.W., Giling, D.P., Klein, A.-M., Eisenhauer, N., 2019. Mapping change in biodiversity and ecosystem function research: food webs foster integration of experiments and science policy. Adv. Ecol. Res. 61, 297-322.

Hirt, M.R., Grimm, V., Li, Y., Rall, B.C., Rosenbaum, B., Brose, U., 2018. Bridging scales: allometric random walks link movement and biodiversity research. Trends Ecol. Evol. 33, 701-712.

Hobbie, S.E., 1992. Effects of Plant Species Nutrient Cycling. Trends Ecol. Evol. 7, 336-339.

Hodapp, D., Hillebrand, H., Blasius, B., Ryabov, A.B., 2016. Environmental and trait variability constrain community structure and the biodiversity-productivity relationship. Ecology 97, 1463-1474.

Hoffmann, A.A., Sgró, C.M., 2011. Climate change and evolutionary adaptation. Nature 470, 479-485.

Hofstetter, R., Dempsey, T., Klepzig, K., Ayres, M., 2007. Temperature-dependent effects on mutualistic, antagonistic, and commensalistic interactions among insects, fungi and mites. Commun. Ecol. 8, 47-56.

Hooper, D.U., Chapin III, F.S., Ewel, J.J., Hector, A., Inchausti, P., Lavorel, S., Lawton, J.H., Lodge, D.M., Loreau, M., Naeem, S., Schmid, B., Setälä, H., et al., 2005. Effects of biodiversity on ecosystem functioning: a consensus of current knowledge. Ecol. Monogr. 75, 3-35.

Huang, Y., Chen, Y., Castro-Izaguirre, N., Baruffol, M., Brezzi, M., Lang, A., Li, Y., Härdtle, W., Von Oheimb, G., Yang, X., Liu, X., Pei, K., et al., 2018. Impacts of species richness on productivity in a large-scale subtropical forest experiment. Science 362, 80-83.

Hughes, A.R., Inouye, B.D., Johnson, M.T.J., Underwood, N., Vellend, M., 2008. Ecological consequences of genetic diversity. Ecol. Lett. 11, 609-623.

Huston, M.A., 1997. Hidden treatments in ecological experiments: re-evaluating the ecosystem function of biodiversity. Oecologia 110, 449-460.

Hutchinson, G.E., 1957. Concluding remarks. In: Cold Spring Harbor Symposia on Quantitative Biology. vol. 22. The Biological Laboratory, Cold Spring Harbor, pp. 415-421.

IPBES, 2018. In: Fischer, M., Rounsevell, M., Torre-Mari, A. (Eds.), Summary for policymakers of the regional assessment report on biodiversity and ecosystem services for Europe and Central Asia of the intergovernmental science-policy platform on biodiversity and ecosystem services. IPBES Secretariat, Bonn, Germany.

IPCC, 2014. Climate Change 2014: Synthesis report. In: Core Writing Team, , Pachauri, R.K., Meyer, L.A. (Eds.), Contribution of Working Groups I, II and III to the Fifth Assessment Report of the Intergovernmental Panel on Climate Change. IPCC, Geneva, Switzerland. 151 pp.

Isbell, F., Calcagno, V., Hector, A., Connolly, J., Harpole, W.S., Reich, P.B., SchererLorenzen, M., Schmid, B., Tilman, D., van Ruijven, J., Weigelt, A., Wilsey, B.J., et al., 2011. High plant diversity is needed to maintain ecosystem services. Nature 477, 199-202.

Isbell, F., Reich, P.B., Tilman, D., Hobbie, S.E., Polasky, S., Binder, S., 2013. Nutrient enrichment, biodiversity loss, and consequent declines in ecosystem productivity. Proc. Natl. Acad. Sci. U. S. A. 110, 11911-11916. 
Isbell, F., Craven, D., Connolly, J., Loreau, M., Schmid, B., Beierkuhnlein, C., Bezemer, T.M., Bonin, C., Bruelheide, H., De Luca, E., Ebeling, A., et al., 2015a. Biodiversity increases the resistance of ecosystem productivity to climate extremes. Nature 526, 574-577.

Isbell, F., Tilman, D., Polasky, S., Loreau, M., 2015b. The biodiversity-dependent ecosystem service debt. Ecol. Lett. 18, 119-134.

Isbell, F., Gonzalez, A., Loreau, M., Cowles, J., Díaz, S., Hector, A., Mace, G.M., Wardle, D.A., O'Connor, M.I., Duffy, J.E., Turnbull, L.A., Thompson, P.L., Larigauderie, A., 2017a. Linking the influence and dependence of people on biodiversity across scales. Nature 546, 65-72.

Isbell, F., Adler, P.R., Eisenhauer, N., Fornara, D., Kimmel, K., Kremen, C., Letourneau, D.K., Liebman, M., Polley, H.W., Quijas, S., Scherer-Lorenzen, M., 2017b. Benefits of increasing plant diversity in sustainable agroecosystems. J. Ecol. 105, 871-879.

Isbell, F., Cowles, J., Dee, L.E., Loreau, M., Reich, P.B., Gonzalez, A., Hector, A., Schmid, B., 2018. Quantifying effects of biodiversity on ecosystem functioning across times and places. Ecol. Lett. 21, 763-778.

Jacquet, C., Mouillot, D., Kulbicki, M., Gravel, D., 2017. Extensions of island biogeography theory predict the scaling of functional trait composition with habitat area and isolation. Ecol. Lett. 20, 135-146.

Janzen, D.H., 1974. The deflowering of Central America. Nat. Hist. 83, 49-53.

Jochum, M., Schneider, F.D., Crowe, T.P., Brose, U., O’Gorman, E.J., 2012. Climateinduced changes in bottom-up and top-down processes independently alter a marine ecosystem. Philos. Trans. R. Soc. B 367, 2962-2970.

Jousset, A., Schmid, B., Scheu, S., Eisenhauer, N., 2011. Genotypic richness and dissimilarity opposingly affect ecosystem functioning. Ecol. Lett. 14, 537-545.

Jousset, A., Eisenhauer, N., Merker, M., Mouquet, N., Scheu, S., 2016. High functional diversity stimulates diversification in experimental microbial communities. Sci. Adv. 2, e1600124.

Jousset, A., Bienhold, C., Chatzinotas, A., Gallien, L., Gobet, A., Kurm, V., Küsel, K., Rillig, M.C., Rivett, D.W., Salles, J.F., van Der Heijden, M.G.A., Youssef, N.H., et al., 2017. Where less may be more: how the rare biosphere pulls ecosystems strings. ISME J. 11, 853-862.

Jucker, T., Avăcăritei, D., Bărnoaiea, I., Duduman, G., Bouriaud, O., Coomes, D.A., 2016. Climate modulates the effects of tree diversity on forest productivity. J. Ecol. 104, 388-398.

Kambach, S., Kühn, I., Castagneyrol, B., Bruelheide, H., 2016. The impact of tree diversity on different aspects of insect herbivory along a global temperature gradient - a metaanalysis. PLoS One 11, 1-14.

Kardol, P., Fanin, N., Wardle, D.A., 2018. Long-term effects of species loss on community properties across contrasting ecosystems. Nature 557, 710-713.

Kettenring, K.M., Mercer, K.L., Reinhardt Adams, C., Hines, J., 2014. Application of genetic diversity-ecosystem function research to ecological restoration. J. Appl. Ecol. 51, 339-348.

Kirwan, L., Lüscher, A., Sebastià, M.T., Finn, J.A., Collins, R.P., Porqueddu, C., Helgadottir, A., Baadshaug, O.H., Brophy, C., Coran, C., Dalmannsdóttir, S., Delgado, I., et al., 2007. Evenness drives consistent diversity effects in intensive grassland systems across 28 European sites. J. Ecol. 95, 530-539.

Kleijn, D., Winfree, R., Bartomeus, I., Carvalheiro, L.G., Henry, M., Isaacs, R., Klein, A.M., Kremen, C., M'Gonigle, L.K., Rader, R., Ricketts, T.H., Williams, N.M., et al., 2015. Delivery of crop pollination services is an insufficient argument for wild pollinator conservation. Nat. Commun. 6, 7414. 
Klein, A.M., Steffan-Dewenter, I., Tscharntke, T., 2003. Fruit set of highland coffee increases with the diversity of pollinating bees. Proc. R. Soc. B Biol. Sci. 270, 955-961.

Knight, T.M., McCoy, M.W., Chase, J.M., McCoy, K.A., Holt, R.D., 2005. Trophic cascades across ecosystems. Nature 437, 880-883.

Kotiaho, J.S., Kaitala, V., Komonen, A., Päivinen, J., 2005. Predicting the risk of extinction from shared ecological characteristics. Proc. Natl. Acad. Sci. U. S. A. 102, 1963-1967.

Laforest-Lapointe, I., Paquette, A., Messier, C., Kembel, S.W., 2017. Leaf bacterial diversity mediates plant diversity and ecosystem function relationships. Nature 546, 145-147.

Lange, M., Eisenhauer, N., Sierra, C.A., Bessler, H., Engels, C., Griffiths, R.I., Mellado-V ázquez, P.G., Malik, A.A., Roy, J., Scheu, S., Steinbeiss, S., Thomson, B.C., et al., 2015. Plant diversity increases soil microbial activity and soil carbon storage. Nat. Commun. 6, 6707.

Lange, M., Koller-France, E., Hildebrandt, A., Oelmann, Y., Wilcke, W., Gleixner, G., 2019. How plant diversity impacts the coupled water, nutrient and carbon cycles. Adv. Ecol. Res. 61, 185-219.

Latz, E., Eisenhauer, N., Rall, B.C., Allan, E., Roscher, C., Scheu, S., Jousset, A., 2012. Plant diversity improves protection against soil-borne pathogens by fostering antagonistic bacterial communities. J. Ecol. 100, 597-604.

Lefcheck, J.S., Byrnes, J.E.K., Isbell, F., Gamfeldt, L., Griffin, J.N., Eisenhauer, N., Hensel, M.J.S., Hector, A., Cardinale, B.J., Duffy, J.E., 2015. Biodiversity enhances ecosystem multifunctionality across trophic levels and habitats. Nat. Commun. 6, 6936.

Lefcheck, J.S., Brandl, S.J., Reynolds, P.L., Smyth, A.R., Meyer, S.T., 2016. Extending rapid ecosystem function assessments to marine ecosystems: a reply to Meyer. Trends Ecol. Evol. 31, 251-253.

Leibold, M.A., Chase, J.M., 2018. Metacommunity ecology. In: Monographs in Population Biology. vol. 59. Princeton University Press.

Leibold, M.A., Holyoak, M., Mouquet, N., Amarasekare, P., Chase, J.M., Hoopes, M.F., Holt, R.D., Shurin, J.B., Law, R., Tilman, D., Loreau, M., Gonzalez, A., 2004. The metacommunity concept: a framework for multi-scale community ecology. Ecol. Lett. 7, 601-613.

Leibold, M.A., Chase, J.M., Ernest, S.K.M., 2017. Community assembly and the functioning of ecosystems: how metacommunity processes alter ecosystems attributes. Ecology 98, 909-919.

Lepš, J., 2004. What do the biodiversity experiments tell us about consequences of plant species loss in the real world? Basic Appl. Ecol. 5, 529-534.

Lindeman, R.L., 1942. The trophic-dynamic aspect of ecology. Ecology 23, 399-417.

Lindenmayer, D.B., Likens, G.E., Franklin, J.F., 2010. Rapid responses to facilitate ecological discoveries from major disturbances. Front. Ecol. Environ. 8, 527-532.

Lipowsky, A., Schmid, B., Roscher, C., 2011. Selection for monoculture and mixture genotypes in a biodiversity experiment. Basic Appl. Ecol. 12, 360-371.

Lipowsky, A., Roscher, C., Schumacher, J., Schmid, B., 2012. Density-independent mortality and increasing plant diversity are associated with differentiation of Taraxacum officinale into r- and K-strategists. PLoS One 7 e28121.

Liu, X., Trogisch, S., He, J.S., Niklaus, P.A., Bruelheide, H., Tang, Z., Erfmeier, A., Scherer-Lorenzen, M., Pietsch, K.A., Yang, B., Kühn, P., Scholten, T., et al., 2018. Tree species richness increases ecosystem carbon storage in subtropical forests. Proc. R. Soc. B Biol. Sci. 285, 20181240.

Loreau, M., 1998. Biodiversity and ecosystem functioning: a mechanistic model. Proc. Natl. Acad. Sci. U. S. A. 95, 5632-5636.

Loreau, M., 2010. Linking biodiversity and ecosystems: towards a unifying ecological theory. Philos. Trans. R. Soc. B 365 (1537), 49-60.

Loreau, M., 2004. Does functional redundancy exist? Oikos 104, 606-611. 
Loreau, M., Hector, A., 2001. Partitioning selection and complementarity in biodiversity experiments. Nature 412, 72-76.

Loreau, M., Naeem, S., Inchausti, P., Bengtsson, J., Grime, J.P., Hector, A., Hooper, D.U., Huston, M.A., Raffaelli, D., Schmid, B., Tilman, D., Wardle, D.A., 2001. Biodiversity and ecosystem functioning: current knowledge and future challenges. Science 294, 804-808.

Loreau, M., Mouquet, N., Gonzalez, A., 2003a. Biodiversity as spatial insurance in heterogeneous landscapes. Proc. Natl. Acad. Sci. U. S. A. 100, 12765-12770.

Loreau, M., Mouquet, N., Holt, R.D., 2003b. Meta-ecosystems: a theoretical framework for a spatial ecosystem ecology. Ecol. Lett. 6, 673-679.

Lozupone, C.A., Stombaugh, J.I., Gordon, J.I., Jansson, J.K., Knight, R., 2012. Diversity, stability and resilience of the human gut microbiota. Nature 489, 220-230.

Lyons, K.G., Brigham, C.A., Traut, B.H., Schwartz, M.W., 2005. Rare species and ecosystem functioning. Conserv. Biol. 19, 1019-1024.

MacArthur, R.H., Wilson, E.O., 1967. The Theory of Island Biogeography. Princeton University Press, Princeton.

Mace, G.M., 2014. Whose conservation? Science 345, 1558-1560.

Maestre, F., Quero, J., Gotelli, N., Escudero, A., Ochoa, V., Delgado-Baquerizo, M., Garcia-Gomez, M., Bowker, M.A., Soliveres, S., Escolar, C., Garcia-Palacios, P., Berdugo, M., 2012. Plant species richness and ecosystem multifunctionality in global drylands. Science 335, 214-219.

Manning, P., Van Der Plas, F., Soliveres, S., Allan, E., Maestre, F.T., Mace, G., Whittingham, M.J., Fischer, M., 2018. Redefining ecosystem multifunctionality. Nat. Ecol. Evol. 2, 427-436.

Manning, P., Loos, J., Barnes, A.D., Batàry, P., Bianchi, F.J.J.A., Buchmann, N., De Deyn, G.B., Ebeling, A., et al., 2019. Transferring biodiversity-ecosystem function research to the management of 'real-world' ecosystems. Adv. Ecol. Res. 61, 323-356.

Maron, J.L., Marler, M., Klironomos, J.N., Cleveland, C.C., 2011. Soil fungal pathogens and the relationship between plant diversity and productivity. Ecol. Lett. 14, 36-41.

Martin-Guay, M.O., Paquette, A., Dupras, J., Rivest, D., 2018. The new Green Revolution: sustainable intensification of agriculture by intercropping. Sci. Total Environ. $615,767-772$.

Maxwell, S.L., Fuller, R.A., Brooks, T.M., Watson, J.E., 2016. Biodiversity: the ravages of guns, nets and bulldozers. Nature News 536 (7615), 143.

McNaughton, S.J., 1977. Diversity and stability of ecological communities: a comment on the role of empiricism in ecology. Am. Nat. 111, 515-525.

MEA, 2005. Millennium Ecosystem Assessment (MEA). www.maweb.org.

Meyer, S.T., Koch, C., Weisser, W.W., 2015. Towards a standardized Rapid Ecosystem Function Assessment (REFA). Trends Ecol. Evol. 30, 390-397.

Meyer, S.T.M., Ebeling, A., Eisenhauer, N., Hertzog, L., Hillebrand, H., Milcu, A., Pompe, S., Abbas, M., Bessler, H., Buchmann, N., De Luca, E., Engels, C., et al., 2016. Effects of biodiversity strengthen over time as ecosystem functioning declines at low and increases at high biodiversity. Ecosphere 7 e01619.

Meyer, S.T., Ptacnik, R., Hillebrand, H., Bessler, H., Buchmann, N., Ebeling, A., Eisenhauer, N., Engels, C., Fischer, M., Halle, S., Klein, A.M., Oelmann, Y., et al., 2018. Biodiversity-multifunctionality relationships depend on identity and number of measured functions. Nat. Ecol. Evol. 2, 44-49.

Milcu, A., Roscher, C., Gessler, A., Bachmann, D., Gockele, A., Guderle, M., Landais, D., Piel, C., Escape, C., Devidal, S., Ravel, O., Buchmann, N., Gleixner, G., Hildebrandt, A., Roy, J., 2014. Functional diversity of leaf nitrogen concentrations drives grassland carbon fluxes. Ecol. Lett. 17, 435-444. 
Mori, A.S., Furukawa, T., Sasaki, T., 2013. Response diversity determines the resilience of ecosystems to environmental change. Biol. Rev. 88, 349-364.

Mori, A.S., Isbell, F., Fujii, S., Makoto, K., Matsuoka, S., Osono, T., 2016. Low multifunctional redundancy of soil fungal diversity at multiple scales. Ecol. Lett. 19, 249-259.

Mori, A.S., Isbell, F., Seidl, R., 2018. $\beta$-Diversity, community assembly, and ecosystem functioning. Trends Ecol. Evol. 33, 549-564.

Morris, P.J., Hanken, J., Lowery, D., Ludäscher, B., Macklin, J., McPhillips, T., Wieczorek, J., Zhang, Q., 2018. Kurator: tools for improving fitness for use of biodiversity data. Biodivers. Inform. Sci. Stand. 2, e26539.

Mouillot, D., Bellwood, D.R., Baraloto, C., Chave, J., Galzin, R., Harmelin-Vivien, M., Kulbicki, M., Lavergne, S., Lavorel, S., Mouquet, N., Paine, C.E.T., Renaud, J., Thuiller, W., 2013. Rare species support vulnerable functions in high-diversity ecosystems. PLoS Biol. 11, e1001569.

Mouquet, N., Moore, J.L., Loreau, M., 2002. Plant species richness and community productivity: why the mechanism that promotes coexistence matters. Ecol. Lett. $5,56-65$.

Mousseau, T.A., Roff, D.A., 1987. Natural selection and the heritability of fitness components. Heredity 59, 181-197.

Mraja, A., Unsicker, S.B., Reichelt, M., Gershenzon, J., Roscher, C., 2011. Plant community diversity influences allocation to direct chemical defence in Plantago lanceolata. PLoS One 6, e28055.

Mulder, C.P.H., Koricheva, J., Huss-Danell, K., Högberg, P., Joshi, J., 1999. Insects affect relationships between plant species richness and ecosystem processes. Ecol. Lett. 2, 237-246.

Murphy, G.E.P., Romanuk, T.N., 2014. A meta-analysis of declines in local species richness from human disturbances. Ecol. Evol. 4, 91-103.

Naeem, S., Li, S., 1997. Biodiversity enhances ecosystem reliability. Nature 390, 507-509.

Naeem, S., Thompson, L.J., Lawler, S.P., Lawton, J.H., Woodfin, R.M., 1994. Declining biodiversity can alter the performance of ecosystems. Nature 368, 734-737.

Naeem, S., Duffy, J.E., Zavaleta, E., 2012. The functions of biological diversity in an age of extinction. Science 336, 1401-1406.

Narum, S.R., Buerkle, C.A., Davey, J.W., Miller, M.R., Hohenlohe, P.A., 2013. Genotyping-by-sequencing in ecological and conservation genomics. Mol. Ecol. $22,2841-2847$.

Newbold, T., Hudson, L.N., Hill, S.L.L., Contu, S., Lysenko, I., Senior, R.A., Börger, L., Bennett, D.J., Choimes, A., Collen, B., Day, J., De Palma, A., et al., 2015. Global effects of land use on local terrestrial biodiversity. Nature 520, 45-50.

Niklaus, P.A., Leadley, P.W., Schmid, B., Körner, C., 2001. A long-term field study on biodiversity $\mathrm{X}$ elevated $\mathrm{CO}_{2}$ interactions in grassland. Eco. Inform. 71, 341-356.

Niklaus, P.A., Le Roux, X., Poly, F., Buchmann, N., Scherer-Lorenzen, M., Weigelt, A., Barnard, R.L., 2016. Plant species diversity affects soil-atmosphere fluxes of methane and nitrous oxide. Oecologia 181, 919-930.

Norberg, J., Swaney, D.P., Dushoff, J., Lin, J., Casagrandi, R., Levin, S.A., 2001. Phenotypic diversity and ecosystem functioning in changing environments: a theoretical framework. Proc. Natl. Acad. Sci. U. S. A. 98, 11376-11381.

O'Connor, M.I., Gonzalez, A., Byrnes, J.E.K., Cardinale, B.J., Duffy, J.E., Gamfeldt, L., Griffin, J.N., Hooper, D., Hungate, B.A., Paquette, A., Thompson, P.L., Dee, L.E., Dolan, K.L., 2017. A general biodiversity-function relationship is mediated by trophic level. Oikos 126, 18-31. 
Oehri, J., Schmid, B., Schaepman-Strub, G., Niklaus, P.A., 2017. Biodiversity promotes primary productivity and growing season lengthening at the landscape scale. Proc. Natl. Acad. Sci. U. S. A. 114, 10160-10165.

Paaby, A.B., Rockman, M.V., 2014. Cryptic genetic variation, evolution's hidden substrate. Nat. Rev. Genet. 15, 247-258.

Paine, C.E.T., Amissah, L., Auge, H., Baraloto, C., Baruffol, M., Bourland, N., Bruelheide, H., Daïnou, K., de Gouvenain, R.C., Doucet, J.L., Doust, S., Fine, P.V.A., et al., 2015. Globally, functional traits are weak predictors of juvenile tree growth, and we do not know why. J. Ecol. 103, 978-989.

Paquette, A., Hector, A., Vanhellemont, M., Koricheva, J., Scherer-Lorenzen, M., Verheyen, K., Abdala-Roberts, L., Auge, H., Barsoum, N., Bauhus, J., Baum, C., Bruelheide, H., et al., 2018. A million and more trees for science. Nat. Ecol. Evol. 2, 763-766.

Pasari, J.R., Levi, T., Zavaleta, E.S., Tilman, D., 2013. Several scales of biodiversity affect ecosystem multifunctionality. Proc. Natl. Acad. Sci. U. S. A. 110 (25), 10219-10222.

Pelletier, F., Garant, D., Hendry, A.P., 2009. Eco-evolutionary dynamics. Philos. Trans. R. Soc. B 364, 1483-1489.

Pennekamp, F., Pontarp, M., Tabi, A., Altermatt, F., Alther, R., Choffat, Y., Fronhofer, E.A., Ganesanandamoorthy, P., Garnier, A., Griffiths, J.I., Greene, S., Horgan, K., et al., 2018. Biodiversity increases and decreases ecosystem stability. Nature 563, 109-112.

Pérès, G., Cluzeau, D., Menasseri, S., Soussana, J.F., Bessler, H., Engels, C., Habekost, M., Gleixner, G., Weigelt, A., Weisser, W.W., Scheu, S., Eisenhauer, N., 2013. Mechanisms linking plant community properties to soil aggregate stability in an experimental grassland plant diversity gradient. Plant Soil 373, 285-299.

Petermann, J.S., Fergus, A.J.F., Turnbull, L.A., Schmid, B., 2008. Janzen-Connell effects are widespread and strong enough to maintain diversity in grasslands. Ecology 89, 2399-2406.

Petermann, J.S., Fergus, A.J.F., Roscher, C., Turnbull, L.A., Weigelt, A., Schmid, B., 2010. Biology, chance, or history? The predictable reassembly of temperate grassland communities. Ecology 91, 408-421.

Pfaff, C.T., Eichenberg, D., Liebergesell, M., König-Ries, B., Wirth, C., 2017. Essential annotation schema for ecology (EASE) - a framework supporting the efficient data annotation and faceted navigation in ecology. PLoS One 12, 1-13.

Poisot, T., Mouquet, N., Gravel, D., 2013. Trophic complementarity drives the biodiversity-ecosystem functioning relationship in food webs. Ecol. Lett. 16, 853-861.

Potthast, T., 2014. The values of biodiversity. In: Lanzerath, D., Minou, F. (Eds.), Concepts and Values in Biodiversity. Routledge, London, pp. 131-146.

Pretty, J., 2018. Intensification for redesigned and sustainable agricultural systems. Science 362, eaav0294.

Ratcliffe, S., Wirth, C., Jucker, T., van der Plas, F., Scherer-Lorenzen, M., Verheyen, K., Allan, E., Benavides, R., Bruelheide, H., Ohse, B., Paquette, A., Ampoorter, E., et al., 2017. Biodiversity and ecosystem functioning relations in European forests depend on environmental context. Ecol. Lett. 20, 1414-1426.

Reich, P.B., Knops, J., Tilman, D., Craine, J.M., Ellsworth, D., Tjoelker, M., Lee, T., Wedin, D., Naeem, S., Bahauddin, D., Hendrey, G., Jose, S., et al., 2001. Plant diversity enhances ecosystem responses to elevated $\mathrm{CO}_{2}$ and nitrogen deposition. Nature 410, 809-812.

Reich, P.B., Tilman, D., Isbell, F., Mueller, K., Hobbie, S.E., Flynn, D.F.B., Eisenhauer, N., 2012. Impacts of biodiversity loss escalate through time as redundancy fades. Science 336, 589-592. 
Ricketts, T.H., Watson, K.B., Koh, I., Ellis, A.M., Nicholson, C.C., Posner, S., Richardson, L.L., Sonter, L.J., 2016. Disaggregating the evidence linking biodiversity and ecosystem services. Nat. Commun. 7, 13106.

Rodrigo, G.P., Henderson, M., Weber, G.H., Ophus, C., Antypas, K., Ramakrishnan, L., 2018. Science search: enabling search through automatic metadata generation. In: 2018 IEEE 14th International Conference on E-Science. IEEE, pp. 93-104.

Roscher, C., Schumacher, J., Baade, J., Wilcke, W., Gleixner, G., Weisser, W.W., Schmid, B., Schulze, E.D., 2004. The role of biodiversity for element cycling and trophic interactions: an experimental approach in a grassland community. Basic Appl. Ecol. 5, 107-121.

Roscher, C., Temperton, V.M., Scherer-Lorenzen, M., Schmitz, M., Schumacher, J., Schmid, B., Buchmann, N., Weisser, W.W., Schulze, E.D., 2005. Overyielding in experimental grassland communities-irrespective of species pool or spatial scale. Ecol. Lett. 8, 419-429.

Roscher, C., Schumacher, J., Foitzik, O., Schulze, E.D., 2007. Resistance to rust fungi in Lolium perenne depends on within-species variation and performance of the host species in grasslands of different plant diversity. Oecologia 153, 173-183.

Roscher, C., Temperton, V.M., Buchmann, N., Schulze, E.D., 2009. Community assembly and biomass production in regularly and never weeded experimental grasslands. Acta Oecol. 35, 206-217.

Roslin, T., Hardwick, B., Novotny, V., Petry, W.K., Andrew, N.R., Asmus, A., Barrio, I.C., Basset, Y., Boesing, A.L., Bonebrake, T.C., Cameron, E.K., Dáttilo, W., et al., 2017. Higher predation risk for insect prey at low latitudes and elevations. Science 356, 742-744.

Rottstock, T., Joshi, J., Kummer, V., Fischer, M., 2014. Higher plant diversity promotes higher diversity of fungal pathogens, while it decreases pathogen infection per plant. Ecology 95, 1907-1917.

Ruiz-González, C., Archambault, E., Laforest-Lapointe, I., del Giorgio, P.A., Kembel, S.W., Messier, C., Nock, C.A., Beisner, B.E., 2018. Soils associated to different tree communities do not elicit predictable responses in lake bacterial community structure and function. FEMS Microbiol. Ecol. 94, fiy115.

Ryo, M., Rillig, M.C., 2017. Statistically reinforced machine learning for nonlinear patterns and variable interactions. Ecosphere 8, e01976.

Savolainen, O., Lascoux, M., Merilä, J., 2013. Ecological genomics of local adaptation. Nat. Rev. Genet. 14, 807-820.

Scherber, C., 2015. Insect responses to interacting global change drivers in managed ecosystems. Curr. Opin. Insect Sci. 11, 56-62.

Scherber, C., Eisenhauer, N., Weisser, W.W., Schmid, B., Voigt, W., Fischer, M., Schulze, E.D., Roscher, C., Weigelt, A., Allan, E., Beler, H., Bonkowski, M., et al., 2010. Bottom-up effects of plant diversity on multitrophic interactions in a biodiversity experiment. Nature 468, 553-556.

Scherer-Lorenzen, M., 2014. The functional role of biodiversity in the context of global change. In: Burslem, D., Coomes, D., Simonson, W. (Eds.), Forests and Global Change. Cambridge University Press, Cambridge, pp. 195-238.

Scherer-lorenzen, A.M., Palmborg, C., Prinz, A., Schulze, E.D., 2003. The role of plant diversity and composition for nitrate leaching in grasslands the role of plant diversity and composition for nitrate leaching in grasslands. Ecology 84, 1539-1552.

Scherer-Lorenzen, M., Schulze, E.D., Don, A., Schumacher, J., Weller, E., 2007. Exploring the functional significance of forest diversity: a new long-term experiment with temperate tree species (BIOTREE). Perspect. Plant Ecol. Evol. Syst. 9, 53-70. 
Schielzeth, H., Husby, A., 2014. Challenges and prospects in genome-wide quantitative trait loci mapping of standing genetic variation in natural populations. Ann. N. Y. Acad. Sci. 1320, 35-57.

Schläpfer, F., Pfisterer, A.B., Schmid, B., 2005. Non-random species extinction and plant production: implications for ecosystem functioning. J. Appl. Ecol. 42, 13-24.

Schmid, B., Hector, A., 2004. The value of biodiversity experiments. Basic Appl. Ecol. $5,535-542$.

Schmid, B., Hector, A., Saha, P., Loreau, M., 2008. Biodiversity effects and transgressive overyielding. J. Plant Ecol. 1, 95-102.

Schmid, M.W., Heichinger, C., Coman Schmid, D., Guthörl, D., Gagliardini, V., Bruggmann, R., Aluri, S., Aquino, C., Schmid, B., Turnbull, L.A., Grossniklaus, U., 2018. Contribution of epigenetic variation to adaptation in Arabidopsis. Nat. Commun. 9, 4446.

Schneider, F.D., Scheu, S., Brose, U., 2012. Body mass constraints on feeding rates determine the consequences of predator loss. Ecol. Lett. 15, 436-443.

Schneider, F.D., Brose, U., Rall, B.C., Guill, C., 2016. Animal diversity and ecosystem functioning in dynamic food webs. Nat. Commun. 7, 12718.

Schnitzer, S.A., Klironomos, J.N., Hillerislambers, J., Kinkel, L.L., Reich, P.B., Xiao, K., Rillig, M.C., Sikes, B.A., Callaway, R.M., Scott, A., van Nes, E.H., Scheffer, M., et al., 2011. Soil microbes drive the classic plant-productivity diversity pattern. Ecology 92, 296-303.

Schöb, C., Brooker, R.W., Zuppinger-Dingley, D., 2018. Evolution of facilitation requires diverse communities. Nat. Ecol. Evol. 2, 1381-1385.

Schuldt, A., Fornoff, F., Bruelheide, H., Klein, A.M., Staab, M., 2017a. Tree species richness attenuates the positive relationship between mutualistic ant-hemipteran interactions and leaf chewer herbivory. Proc. R. Soc. B Biol. Sci. 284, 20171489.

Schuldt, A., Hönig, L., Li, Y., Fichtner, A., Härdtle, W., von Oheimb, G., Welk, E., Bruelheide, H., 2017b. Herbivore and pathogen effects on tree growth are additive, but mediated by tree diversity and plant traits. Ecol. Evol. 7, 7462-7474.

Schuldt, A., Assmann, T., Brezzi, M., Buscot, F., Eichenberg, D., Gutknecht, J., Härdtle, W., He, J.S., Klein, A.M., Kühn, P., Liu, X., Ma, K., et al., 2018. Biodiversity across trophic levels drives multifunctionality in highly diverse forests. Nat. Commun. 9, 2989.

Schuldt, A., Ebeling, A., Kunz, M., Staab, M., Guimarães-Steinicke, C., Bachmann, D., Buchmann, N., Durka, W., Fichtner, A., Fornoff, F., Härdtle, W., Hertzog, L., et al., 2019. Multiple plant diversity components drive consumer communities across ecosystems. Nat. Commun. 10, 1460.

Schulze, E.D., Mooney, H.A., 1994. Biodiversity and Ecosystem Function. Springer, Berlin, Heidelberg.

Schwarz, B., Barnes, A.D., Thakur, M.P., Brose, U., Ciobanu, M., Reich, P.B., Rich, R.L., Rosenbaum, B., Stefanski, A., Eisenhauer, N., 2017. Warming alters energetic structure and function but not resilience of soil food webs. Nat. Clim. Change 7, 895-900.

Seabloom, E.W., Kinkel, L., Borer, E.T., Hautier, Y., Montgomery, R.A., Tilman, D., 2017. Food webs obscure the strength of plant diversity effects on primary productivity. Ecol. Lett. 20, 505-512.

Seibold, S., Brandl, R., Buse, J., Hothorn, T., Schmidl, J., Thorn, S., Müller, J., 2015. Association of extinction risk of saproxylic beetles with ecological degradation of forests in Europe. Conserv. Biol. 29, 382-390.

Seibold, S., Cadotte, M.W., MacIvor, J.S., Thorn, S., Müller, J., 2018. The necessity of multitrophic approaches in community ecology. Trends Ecol. Evol. 33, 754-764.

Sobral, M., Silvius, K.M., Overman, H., Oliveira, L.F.B., Raab, T.K., Fragoso, J.M.V., 2017. Mammal diversity influences the carbon cycle through trophic interactions in the Amazon. Nat. Ecol. Evol. 1, 1670-1676. 
Soliveres, S., van der Plas, F., Manning, P., Prati, D., Gossner, M.M., Renner, S.C., Alt, F., Arndt, H., Baumgartner, V., Binkenstein, J., Birkhofer, K., Blaser, S., et al., $2016 a$. Biodiversity at multiple trophic levels is needed for ecosystem multifunctionality. Nature 536, 456-459.

Soliveres, S., Manning, P., Prati, D., Gossner, M.M., Alt, F., Arndt, H., Baumgartner, V., Binkenstein, J., Birkhofer, K., Blaser, S., Blüthgen, N., Boch, S., et al., 2016b. Locally rare species influence grassland ecosystem multifunctionality. Philos. Trans. R. Soc. B 371, 20150269.

Spiesman, B.J., Stapper, A.P., Inouye, B.D., 2018. Patch size, isolation, and matrix effects on biodiversity and ecosystem functioning in a landscape microcosm. Ecosphere 9, e02173.

Stachowicz, J.J., Bruno, J.F., Duffy, J.E., 2007. Understanding the effects of marine biodiversity on communities and ecosystems. Annu. Rev. Ecol. Evol. Syst. 38, 739-766.

Stachowicz, J.J., Best, R.J., Bracken, M.E.S., Graham, M.H., 2008a. Complementarity in marine biodiversity manipulations: reconciling divergent evidence from field and mesocosm experiments. Proc. Natl. Acad. Sci. U. S. A. 105, 18842-18847.

Stachowicz, J.J., Graham, M., Bracken, M.E.S., Szoboszlai, A.I., 2008b. Diversity enhances cover and stability of seaweed assemblages: the role of heterogeneity and time. Ecology 89, 3008-3019.

Stapley, J., Reger, J., Feulner, P.G.D., Smadja, C., Galindo, J., Ekblom, R., Bennison, C., Ball, A.D., Beckerman, A.P., Slate, J., 2010. Adaptation genomics: the next generation. Trends Ecol. Evol. 25, 705-712.

Steinauer, K., Jensen, B., Strecker, T., Luca, E., Scheu, S., Eisenhauer, N., 2016. Convergence of soil microbial properties after plant colonization of an experimental plant diversity gradient. BMC Ecol. 16, 19.

Steudel, B., Hector, A., Friedl, T., Löfke, C., Lorenz, M., Wesche, M., Kessler, M., 2012. Biodiversity effects on ecosystem functioning change along environmental stress gradients. Ecol. Lett. 15, 1397-1405.

Stocker, R., Korner, C., Schmid, B., Niklaus, P.A., Leadley, P.W., 1999. A field study of the effects of elevated $\mathrm{CO}_{2}$ and plant species diversity on ecosystem-level gas exchange in a planted calcareous grassland. Glob. Chang. Biol. 5, 95-105.

Suding, K.N., Collins, S.L., Gough, L., Clark, C., Cleland, E.E., Gross, K.L., Milchunas, D.G., Pennings, S., 2005. Functional- and abundance-based mechanisms explain diversity loss due to N fertilization. Proc. Natl. Acad. Sci. U. S. A. 102, 4387-4392.

Swift, M.J., Izac, A.M.N., van Noordwijk, M., 2004. Biodiversity and ecosystem services in agricultural landscapes_-are we asking the right questions? Agric. Ecosyst. Environ. 104, 113-134.

Thakur, M.P., Milcu, A., Manning, P., Niklaus, P.A., Roscher, C., Power, S., Reich, P.B., Scheu, S., Tilman, D., Ai, F., Guo, H., Ji, R., et al., 2015. Plant diversity drives soil microbial biomass carbon in grasslands irrespective of global environmental change factors. Glob. Chang. Biol. 21, 4076-4085.

Thakur, M.P., Tilman, D., Purschke, O., Ciobanu, M., Cowles, J., Isbell, F., Wragg, P.D., Eisenhauer, N., 2017. Climate warming promotes species diversity, but with greater taxonomic redundancy, in complex environments. Sci. Adv. 3 e1700866.

Thebault, E., Loreau, M., 2003. Food-web constraints on biodiversity-ecosystem functioning relationships. Proc. Natl. Acad. Sci. U. S. A. 100, 14949-14954.

Thompson, P.L., Gonzalez, A., 2016. Ecosystem multifunctionality in metacommunities. Ecology 97, 2867-2879.

Thompson, R.M., Brose, U., Dunne, J.A., Hall, R.O., Hladyz, S., Kitching, R.L., Martinez, N.D., Rantala, H., Romanuk, T.N., Stouffer, D.B., Tylianakis, J.M., 2012. Food webs: reconciling the structure and function of biodiversity. Trends Ecol. Evol. 27, 689-697. 
Thompson, P.L., Isbell, F., Loreau, M., O'connor, M.I., Gonzalez, A., 2018. The strength of the biodiversity-ecosystem function relationship depends on spatial scale. Proc. R. Soc. B Biol. Sci. 285, 20180038.

Thorn, S., Bässler, C., Bernhardt-Römermann, M., Cadotte, M., Heibl, C., Schäfer, H., Seibold, S., Müller, J., 2016. Changes in the dominant assembly mechanism drive species loss caused by declining resources. Ecol. Lett. 19, 163-170.

Tiede, J., Wemheuer, B., Traugott, M., Daniel, R., Tscharntke, T., Ebeling, A., Scherber, C., 2016. Trophic and non-trophic interactions in a biodiversity experiment assessed by next- generation sequencing. PLoS One 11 e0148781.

Tilman, D., Downing, J.A., 1994. Biodiversity and stability in grasslands. Nature 367, 363-365.

Tilman, D., Snell-Rood, E.C., 2014. Diversity breeds complementarity. Nature 515, 44.

Tilman, D., Lehman, C.L., Thompson, K.T., 1997a. Plant diversity and ecosystem productivity: theoretical considerations. Proc. Natl. Acad. Sci. U. S. A. 94, 1857-1861.

Tilman, D., Knops, J., Wedin, D., Reich, P., Ritchie, M., Siemann, E., 1997b. The influence of functional diversity and composition on ecosystem processes. Science 277, 1300-1302.

Tilman, D., Hill, J., Lehman, C., 2006. Carbon-negative biofuels from low-input highdiversity grassland biomass. Science 314, 1598-1600.

Tilman, D., Isbell, F., Cowles, J.M., 2014. Biodiversity and ecosystem function. Annu. Rev. Ecol. Evol. Syst. 45, 471-493.

Trenbath, B.R., 1974. Biomass productivity of mixtures. Adv. Agron. 26, 177-210.

Trogisch, S., Schuldt, A., Bauhus, J., Blum, J.A., Both, S., Buscot, F., Castro-Izaguirre, N., Chesters, D., Durka, W., Eichenberg, D., Erfmeier, A., Fischer, M., et al., 2017. Toward a methodical framework for comprehensively assessing forest multifunctionality. Ecol. Evol. 7, 10652-10674.

Tscharntke, T., Tylianakis, J.M., Rand, T.A., Didham, R.K., Fahrig, L., Batáry, P., Bengtsson, J., Clough, Y., Crist, T.O., Dormann, C.F., Ewers, R.M., Fründ, J., et al., 2012. Landscape moderation of biodiversity patterns and processes-eight hypotheses. Biol. Rev. 87, 661-685.

Turnbull, L.A., Levine, J.M., Loreau, M., Hector, A., 2013. Coexistence, niches and biodiversity effects on ecosystem functioning. Ecol. Lett. 16, 116-127.

Turnbull, L.A., Isbell, F., Purves, D.W., Loreau, M., Hector, A., 2016. Understanding the value of plant diversity for ecosystem functioning through niche theory. Proc. R. Soc. B Biol. Sci. 283, 20160536.

Tylianakis, J.M., Didham, R.K., Bascompte, J., Wardle, D.A., 2008. Global change and species interactions in terrestrial ecosystems. Ecol. Lett. 11, 1351-1363.

Urban, M.C., Bocedi, G., Hendry, A.P., Mihoub, J.B., Pe'er, G., Singer, A., Bridle, J.R., Crozier, L.G., De Meester, L., Godsoe, W., Gonzalez, A., Hellmann, J.J., et al., 2016. Improving the forecast for biodiversity under climate change. Science 353, aad8466.

Valverde-Barrantes, O.J., Freschet, G.T., Roumet, C., Blackwood, C.B., 2017. A worldview of root traits: the influence of ancestry, growth form, climate and mycorrhizal association on the functional trait variation of fine-root tissues in seed plants. New Phytol. 215, 1562-1573.

van der Heijden, M.G.A., Klironomos, J.N., Ursic, M., Moutoglis, P., Streitwolf-Engel, R., Boller, T., Wiemken, A., Sanders, I.R., 1998. Mycorrhizal fungal diversity determines plant biodiversity, ecosystem variability and productivity. Nature 74, 69-72.

van der Plas, F., 2019. Biodiversity and ecosystem functioning in naturally assembled communities. Biol. Rev. 94, 1220-1245.

van der Plas, F., Manning, P., Allan, E., Scherer-Lorenzen, M., Verheyen, K., Wirth, C., Zavala, M.A., et al., 2016a. Jack-of-all-trades effects drive biodiversity-ecosystem multifunctionality relationships in European forests. Nat. Commun. 7, 11109. 
van der Plas, F., Manning, P., Soliveres, S., Allan, E., Scherer-Lorenzen, M., Verheyen, K., Wirth, C., Zavala, M.A., Ampoorter, E., Baeten, L., Barbaro, L., Bauhus, J., et al., 2016b. Biotic homogenization can decrease landscape-scale forest multifunctionality. Proc. Natl. Acad. Sci. U. S. A. 113, 3557-3562.

van der Plas, F., Ratcliffe, S., Ruiz-Benito, P., Scherer-Lorenzen, M., Verheyen, K., Wirth, C., Zavala, M.A., Ampoorter, E., Baeten, L., Barbaro, L., Bastias, C.C., Bauhus, J., et al., 2018. Continental mapping of forest ecosystem functions reveals a high but unrealised potential for forest multifunctionality. Ecol. Lett. 21, 31-42.

Van Kleunen, M., Dawson, W., Essl, F., Pergl, J., Winter, M., Weber, E., Kreft, H., Weigelt, P., Kartesz, J., Nishino, M., Antonova, L.A., Barcelona, J.F., et al., 2015. Global exchange and accumulation of non-native plants. Nature 525, 100.

van Moorsel, S.J., Hahl, T., Wagg, C., De Deyn, G.B., Flynn, D.F.B., Zuppinger-Dingley, D., Schmid, B., 2018. Community evolution increases plant productivity at low diversity. Ecol. Lett. 21, 128-137.

van Ruijven, J., Berendse, F., 2003. Positive effects of plant species diversity on productivity in the absence of legumes. Ecol. Lett. 6, 170-175.

Vandermeer, J.H., 1981. The interference production principle: an ecological theory for agriculture. Bioscience 31, 361-364.

Vandermeer, J.H., 1990. Intercropping. In: Carroll, C.R., Vandermeer, J.H., Rosset, P. (Eds.), Agroecology. McGraw-Hill, New York, pp. 481-516.

Veiga, A.K., Saraiva, A.M., Chapman, A.D., Morris, P.J., Gendreau, C., Schigel, D., Robertson, T.J., 2017. A conceptual framework for quality assessment and management of biodiversity data. PLoS One 12, e0178731.

Vellend, M., Geber, M.A., 2005. Connections between species diversity and genetic diversity. Ecol. Lett. 8, 767-781.

Verheyen, K., Vanhellemont, M., Auge, H., Baeten, L., Baraloto, C., Barsoum, N., Bilodeau-Gauthier, S., Bruelheide, H., Castagneyrol, B., Godbold, D., Haase, J., Hector, A., et al., 2016. Contributions of a global network of tree diversity experiments to sustainable forest plantations. Ambio 45, 29-41.

Vitousek, P.M., D’Antonio, C.M., Loope, L.L., Rejmanek, M., Westbrooks, R., 1997. Introduced species: A significant component of human-caused global change. N. Z. J. Ecol. 21, 1-16.

Vogel, A., Scherer-Lorenzen, M., Weigelt, A., 2012. Grassland resistance and resilience after drought depends on management intensity and species richness. PLoS One 7, e36992.

Vogel, A., Manning, P., Cadotte, M.W., Cowles, J., Isbell, F., Jousset, A.C., Kimmel, K., Meyer, S.T., et al., 2019a. Lost in trait space: species-poor communities are inflexible in properties that drive ecosystem functioning. Adv. Ecol. Res. 61, 91-131.

Vogel, A., Ebeling, A., Gleixner, G., Roscher, C., Scheu, S., Ciobanu, M., Koller-France, E., Lange, M., et al., 2019b. A new experimental approach to test why biodiversity effects strengthen as ecosystems age. Adv. Ecol. Res. 61, 221-264.

Voigt, W., Perner, J., Davis, A.J., Eggers, T., Schumacher, J., Bährmann, R., Fabian, B., Heinrich, W., Köhler, G., Lichter, D., Marstaller, R., Sander, F.W., 2003. trophic levels are differentially sensitive to climate. Ecology 84, 2444-2453.

Wacker, L., Baudois, O., Eichenberger-Glinz, S., Schmid, B., 2008. Environmental heterogeneity increases complementarity in experimental grassland communities. Basic Appl. Ecol. 9, 467-474.

Wall, D.H., Nielsen, U.N., Six, J., 2015. Soil biodiversity and human health. Nature 528, 69-76.

Wang, S., Brose, U., 2018. Biodiversity and ecosystem functioning in food webs: the vertical diversity hypothesis. Ecol. Lett. 21, 9-20.

Wang, L., Delgado-Baquerizo, M., Wang, D., Isbell, F., Liu, J., Zhu, H., Zhong, Z., Liu, J., Yuan, X., Feng, C., Chang, Q., 2019. Diversifying livestock promotes multidiversity and multifunctionality in managed grasslands. Proc. Natl. Acad. Sci. U. S. A. 116 (13), 6187-6192. 
Wardle, D.A., 2016. Do experiments exploring plant diversity-ecosystem functioning relationships inform how biodiversity loss impacts natural ecosystems? J. Veg. Sci. 27, 646-653.

Wardle, D.A., Zackrisson, O., 2005. Effects of species and functional group loss on island ecosystem properties. Nature 435, 806-810.

Wardle, D.A., Bardgett, R.D., Callaway, R.M., van der Putten, W.H., 2011. Terrestrial ecosystem responses to species gains and losses. Science 332, 1273-1277.

Weigelt, A., Weisser, W.W., Buchmann, N., Scherer-Lorenzen, M., 2009. Biodiversity for multifunctional grasslands: equal productivity in high-diversity low-input and low-diversity high-input systems. Biogeosciences 6, 1695-1706.

Weisser, W.W., Roscher, C., Meyer, S.T., Ebeling, A., Luo, G., Allan, E., Beßler, H., Barnard, R.L., Buchmann, N., Buscot, F., Engels, C., Fischer, C., et al., 2017. Biodiversity effects on ecosystem functioning in a 15-year grassland experiment: patterns, mechanisms, and open questions. Basic Appl. Ecol. 23, 1-73.

Wilkinson, M.D., Dumontier, M., Aalbersberg, I.J., Appleton, G., Axton, M., Baak, A., Blomberg, N., Boiten, J.W., da Silva Santos, L.B., Bourne, P.E., Bouwman, J., Brookes, A.J., 2016. The fair guiding principles for scientific data management and stewardship. Sci. Data 3, 160018.

Wilsey, B.J., Polley, H.W., 2004. Realistically low species evenness does not alter grassland species-richness-productivity relationships. Ecology 85, 2693-2700.

Winfree, R., Reilly, J.R., Bartomeus, I., Cariveau, D.P., Williams, N.M., Gibbs, J., 2018. Species turnover promotes the importance of bee diversity for crop pollination at regional scales. Science 359, 791-793.

Worm, B., Duffy, J.E., 2003. Biodiversity, productivity and stability in real food webs. Trends Ecol. Evol. 18, 628-632.

Wright, A.J., Schnitzer, S.A., Reich, P.B., 2014. Size matters when living close to your neighbors - the importance of both competition and facilitation in plant communities. Ecology 95, 2213-2223.

Wright, A.J., Ebeling, A., De Kroon, H., Roscher, C., Weigelt, A., Buchmann, N., Buchmann, T., Fischer, C., Hacker, N., Hildebrandt, A., Leimer, S., et al., 2015. Flooding disturbances increase resource availability and productivity but reduce stability in diverse plant communities. Nat. Commun. 6, 6092.

Wright, A.J., Wardle, D.A., Callaway, R., Gaxiola, A., 2017. The overlooked role of facilitation in biodiversity experiments. Trends Ecol. Evol. 32, 383-390.

Wuest, S.E., Niklaus, P.A., 2018. A plant biodiversity effect resolved to a single chromosomal region. Nat. Ecol. Evol. 2, 1933-1939.

Yachi, S., Loreau, M., 1999. Biodiversity and ecosystem productivity in a fluctuating environment: the insurance hypothesis. Proc. Natl. Acad. Sci. U. S. A. 96, 1463-1468.

Yang, J., Cao, M., Swenson, N.G., 2018. Why functional traits do not predict tree demographic rates. Trends Ecol. Evol. 33, 326-336.

Zavaleta, E.S., Pasari, J.R., Hulvey, K.B., Tilman, G.D., 2010. Sustaining multiple ecosystem functions in grassland communities requires higher biodiversity. Proc. Natl. Acad. Sci. U. S. A. 107, 1443-1446.

Zeng, X., Durka, W., Fischer, M., 2017. Species-specific effects of genetic diversity and species diversity of experimental communities on early tree performance. J. Plant Ecol. 10, 252-258.

Zhang, Q.G., Zhang, D.Y., 2006. Resource availability and biodiversity effects on the productivity, temporal variability and resistance of experimental algal communities. Oikos 114, 385-396.

Zuppinger-Dingley, D., Schmid, B., Petermann, J.S., Yadav, V., De Deyn, G.B., Flynn, D.F.B., 2014. Selection for niche differentiation in plant communities increases biodiversity effects. Nature 515, 108-111.

Zuppinger-Dingley, D., Flynn, D.F.B., De Deyn, G.B., Petermann, J.S., Schmid, B., 2016. Plant selection and soil legacy enhance long-term biodiversity effects. Ecology 97, 918-928. 